\title{
Article \\ Quantitative Proteomics and Differential Protein Abundance Analysis after the Depletion of PEX3 from Human Cells Identifies Additional Aspects of Protein Targeting to the ER
}

\author{
Richard Zimmermann ${ }^{1, *} \mathbb{D}$, Sven Lang ${ }^{1}\left(\mathbb{D}\right.$, Monika Lerner ${ }^{1}$, Friedrich Förster ${ }^{2} \oplus$, Duy Nguyen ${ }^{3}$, \\ Volkhard Helms ${ }^{3}$ iD and Bianca Schrul ${ }^{1, *}$ \\ 1 Medical Biochemistry and Molecular Biology, Saarland University, 66421 Homburg, Germany; \\ sven.lang@uni-saarland.de (S.L.); monika.lerner@uks.eu (M.L.) \\ 2 Bijvoet Center for Biomolecular Research, Utrecht University, $3584 \mathrm{CH}$ Utrecht, The Netherlands; \\ f.g.forster@uu.nl \\ 3 Center for Bioinformatics, Saarland Informatics Campus, Saarland University, 66041 Saarbrücken, Germany; \\ duy.nguyen@dkfz-heidelberg.de (D.N.); volkhard.helms@bioinformatik.uni-saarland.de (V.H.) \\ * Correspondence: richard.zimmermann@uks.eu (R.Z.); Bianca.Schrul@uks.eu (B.S.)
}

\section{check for} updates

Citation: Zimmermann, R.; Lang, S.; Lerner, M.; Förster, F.; Nguyen, D.; Helms, V.; Schrul, B. Quantitative Proteomics and Differential Protein Abundance Analysis after the Depletion of PEX3 from Human Cells Identifies Additional Aspects of Protein Targeting to the ER. Int. J. Mol. Sci. 2021, 22, 13028. https://doi.org/ $10.3390 /$ ijms222313028

Academic Editor: Isao Ishii

Received: 29 September 2021 Accepted: 29 November 2021 Published: 1 December 2021

Publisher's Note: MDPI stays neutral with regard to jurisdictional claims in published maps and institutional affiliations.

Copyright: (c) 2021 by the authors Licensee MDPI, Basel, Switzerland. This article is an open access article distributed under the terms and conditions of the Creative Commons Attribution (CC BY) license (https:// creativecommons.org/licenses/by/ $4.0 /)$

\begin{abstract}
Protein import into the endoplasmic reticulum (ER) is the first step in the biogenesis of around 10,000 different soluble and membrane proteins in humans. It involves the co- or posttranslational targeting of precursor polypeptides to the ER, and their subsequent membrane insertion or translocation. So far, three pathways for the ER targeting of precursor polypeptides and four pathways for the ER targeting of mRNAs have been described. Typically, these pathways deliver their substrates to the Sec61 polypeptide-conducting channel in the ER membrane. Next, the precursor polypeptides are inserted into the ER membrane or translocated into the ER lumen, which may involve auxiliary translocation components, such as the TRAP and Sec62/Sec63 complexes, or auxiliary membrane protein insertases, such as EMC and the TMCO1 complex. Recently, the PEX19/PEX3-dependent pathway, which has a well-known function in targeting and inserting various peroxisomal membrane proteins into pre-existent peroxisomal membranes, was also found to act in the targeting and, putatively, insertion of monotopic hairpin proteins into the ER. These either remain in the ER as resident ER membrane proteins, or are pinched off from the ER as components of new lipid droplets. Therefore, the question arose as to whether this pathway may play a more general role in ER protein targeting, i.e., whether it represents a fourth pathway for the ER targeting of precursor polypeptides. Thus, we addressed the client spectrum of the PEX19/PEX3-dependent pathway in both PEX3-depleted HeLa cells and PEX3-deficient Zellweger patient fibroblasts by an established approach which involved the label-free quantitative mass spectrometry of the total proteome of depleted or deficient cells, as well as differential protein abundance analysis. The negatively affected proteins included twelve peroxisomal proteins and two hairpin proteins of the ER, thus confirming two previously identified classes of putative PEX19/PEX3 clients in human cells. Interestingly, fourteen collagen-related proteins with signal peptides or N-terminal transmembrane helices belonging to the secretory pathway were also negatively affected by PEX3 deficiency, which may suggest compromised collagen biogenesis as a hitherto-unknown contributor to organ failures in the respective Zellweger patients.
\end{abstract}

Keywords: endoplasmic reticulum; lipid droplets; peroxisomes; PEX3; protein targeting; membrane protein insertion; protein translocation; label-free quantitative mass spectrometry; differential protein abundance analysis; Zellweger syndrome

\section{Introduction}

Analogously to the division of the human body into several organs, the nucleated human cell is divided into various different compartments, the cell organelles, which are 
surrounded — and thereby separated from the cytosol—by biological membranes. However, the vast majority of the approximately 30,000 types of the polypeptides-along with their isoforms-of a human cell are synthesized in the cytosol. Therefore, the proteins of the different organelles have to be sorted to the correct organelles and, subsequently, inserted into or translocated across the organellar membrane(s). The protein import into the endoplasmic reticulum (ER) is the first step in the biogenesis of about 10,000 different soluble and membrane proteins of human cells [1-4]. These were found to fulfill their functions in the membrane or lumen of the ER, along with the nuclear envelope, in one of the organelles belonging to the pathways of endo- and exocytosis (i.e., ERGIC, Golgi apparatus, endosome, lysosome, transport vesicles), or at the cell surface as plasma membraneor secretory-proteins. Excluding resident proteins of the ER, most of the correctly folded and assembled proteins are delivered from the ER to their functional location by vesicular transport, which involves vesicles budding off from subdomains of the tubular ER, which are termed "exit sites" (ERES) $[5,6]$. In recent years, however, an increasing number of proteins destined to lipid droplets (LDs), peroxisomes or mitochondria were observed to be targeted to the ER as well, prior to their integration into budding LDs or peroxisomes, or prior to their delivery to mitochondria via the recently-identified ER-SURF pathway [7-11]. LDs and peroxisomes are ER-derived organelles, and their biogenesis occurs in specialized subdomains of the tubular ER $[8,10]$.

Protein import into the ER involves ER membrane targeting as the initial step, and the insertion of nascent or fully-synthesized membrane proteins into-or the translocation of soluble precursor polypeptides across-the ER membrane as the second step [1-4]. Typically, both processes depend on N-terminal signal peptides (SPs) or transmembrane helices (TMHs) in the precursor polypeptides that serve as signals [4,12-14]. Generally, the Sec61 complex of the ER membrane represents the entry point for most of these precursor polypeptides into the organelle (Table 1) [1-4]. A variety of proteins rely on the Sec61 complex for their integration into the ER lumen or their translocation across the ER membrane (Figure 1a). These include SP-containing soluble or GPI-anchored proteins, bitopic type I (C-in N-out) and type II (N-in C-out) proteins, and multispanning membrane proteins. Sec61 is also implicated in the membrane insertion of proteins without $\mathrm{N}$-terminal SPs, such as type III (C-in N-out) [4] and C-tail-anchored (TA) (N-in C-out) membrane proteins [15-17], and even monotopic hairpin proteins (C-in $\mathrm{N}$-in) $[18,19]$. In these cases, however, the role of Sec61 is less clear, and auxiliary factors such as the TRAP complex, the Sec62/Sec63 complex, or insertases such as the ER membrane protein complex (EMC) or the TMCO1 complex are required in addition [4]. Especially the membrane insertion of TAproteins predominantly relies on the insertase WRB/CAML [15-17]. In conclusion, several co- and post-translational protein targeting pathways merge at the Sec61 complex in the ER membrane, including the co-translational SRP/SR-pathway and the post-translational SRP-independent or SND pathways [2,4,20-26].

In addition, there is the targeting of mRNAs to the ER membrane, which involves mRNA receptors (such as KTN1), or receptors for ribosome nascent chain complexes with nascent chains, which are not yet long enough to be able to interact with SRP (such as RRBP1) [27-33]. However, one general lesson from the analysis of all these pathways is that they are not strictly separated from each other, and there are at least some precursor polypeptides which can be targeted to the ER by more than one pathway (such as some small presecretory proteins and some tail-anchored membrane proteins) $[23,25,26]$. Thus, the targeting pathways have overlapping substrate specificities, and can substitute for each other, at least to a certain extent. The characterization of all of these pathways and mechanisms is also of medical importance, as several of the components are linked to human hereditary or tumor diseases, or are hijacked by viral or bacterial agents [34].

Recent work identified the PEX19/PEX3-dependent pathway as a fourth pathway for the ER targeting of precursor polypeptides [35,36]. PEX3 (also termed peroxisomal biogenesis factor 3 or Peroxin-3) was first identified in yeast, and is a membrane protein with an $\mathrm{N}$-terminal transmembrane domain and a large $\mathrm{C}$-terminal domain, which faces 
the cytosol both in yeast and in humans [37-41]. Originally, it was characterized as a peroxisomal membrane protein, which cooperates with the cytosolic protein PEX19 in the targeting of peroxisomal membrane proteins to pre-existent peroxisomes and in the facilitation of their membrane insertion [38,40]. However, PEX3 is also present in discrete subdomains of ER membranes, and is involved in the targeting of an unknown number of precursor proteins to ER membranes, and possibly in their membrane insertion [35,36]. So far, these precursor proteins include membrane proteins, which either remain in the ER (the two-hairpin or reticulon-domain containing proteins ARL6IP1, RTN3A, and RTN4C) [35] or are pinched off in LDs (such as the hairpin protein UBXD8) [36]. At the ER, PEX3 cooperates with the farnesylated variant of PEX19 [36,39]. Thus, the farnesylation of PEX19 is most likely decisive in delivering precursor polypeptides to either pre-existent peroxisomes or the ER $[7,8]$. These observations raised the question of whether this pathway may play a more general role in ER protein targeting. Defects in the human PEX3 gene are linked to a particularly devastating form of Zellweger syndrome, which belongs to the peroxisome biogenesis disorders, and is also termed "cerebro-hepato-renal syndrome" to indicate the most important affected organs [41-44]. Infants with the disease typically die within their first year of life because of the complete absence of peroxisomes in all of the cells of the body.

Here, we address the client spectrum of PEX3 in ER protein targeting in human cells and, simultaneously, the question of whether the PEX19/PEX3-dependent pathway to the ER can also target precursor polypeptides to the Sec61 complex. The approach involves transiently PEX3-depleted HeLa cells or chronically PEX3-deficient Zellweger patient fibroblasts in combination with differential proteomic analysis by label-free quantitative mass spectrometry (MS) and differential protein abundance analysis (Figure 1b). Thus, we report on negatively and positively affected proteins after the partial depletion of PEX3 in HeLa cells and in PEX3-deficient Zellweger patient fibroblasts.

Table 1. Protein transport components and associated proteins in HeLa cells and linked diseases.

\begin{tabular}{|c|c|c|c|}
\hline Component/Subunit for ER Targeting & Abundance $^{1}$ & Localization $^{2}$ & Linked Diseases \\
\hline \#p34 (LRC59, LRRC59) ${ }^{3}$ & 2480 & ERM & \\
\hline \#p180 (RRBP1) & 135 & ERM & $\begin{array}{c}\text { Hepatocellular Carcinoma, Colorectal } \\
\text { Cancer }\end{array}$ \\
\hline Kinectin 1 (KTN1) & 263 & ERM & \\
\hline AEG-1 (LYRIC, MTDH) & 575 & ERM & \\
\hline$\# S R P^{4}$ & & $\mathrm{C}$ & \\
\hline - SRP72 & 355 & & Aplasia, Myelodysplasia \\
\hline$-\quad$ SRP68 & 197 & & \\
\hline - $\quad$ SRP54 & 228 & & $\begin{array}{l}\text { Neutropenia, Pancreas } \\
\text { Insufficiency }\end{array}$ \\
\hline - SRP19 & 33 & & \\
\hline - SRP14 & 4295 & & \\
\hline - SRP9 & 3436 & & \\
\hline - $\quad$ 7SL RNA & & & \\
\hline$S R P$ receptor & & ERM & \\
\hline - SR $\alpha$ (docking protein) & 249 & & \\
\hline$-\operatorname{SR} \beta$ & 173 & & \\
\hline Calmodulin & 9428 & $\mathrm{C}$ & \\
\hline \multicolumn{4}{|l|}{$\begin{array}{l}\text { for ER targeting and, possibly, for membrane } \\
\text { integration }\end{array}$} \\
\hline hSnd1 & unknown & & \\
\hline Snd receptor & & ERM & \\
\hline - $\quad$ hSnd2 (TMEM208) & 81 & & \\
\hline$-\quad \mathrm{hSnd} 3 \S$ & 49 & & \\
\hline PEX19 & 80 & $\mathrm{C}$ & Zellweger Syndrome \\
\hline PEX3 & 103 & ERM, PexM & Zellweger Syndrome \\
\hline
\end{tabular}


Table 1. Cont.

\begin{tabular}{|c|c|c|c|}
\hline Component/Subunit for ER Targeting & Abundance ${ }^{1}$ & Localization $^{2}$ & Linked Diseases \\
\hline \multicolumn{4}{|l|}{ for ER targeting plus membrane integration } \\
\hline \#Bag6 complex & & $\mathrm{C}$ & \\
\hline - TRC35 (Get4) & 171 & & \\
\hline$-\quad \mathrm{Ubl} 4 \mathrm{~A}$ & 177 & & \\
\hline - Bag6 (Bat3) & 133 & & \\
\hline SGTA & 549 & $\mathrm{C}$ & \\
\hline TRC40 (Asna1, Get3) & 381 & C & \\
\hline TA receptor & & ERM & \\
\hline - $\quad$ CAML (CAMLG, Get2) & 5 & & \\
\hline - $\quad$ WRB (CHD5, Get1) & 4 & & Congenital Heart Disease \\
\hline
\end{tabular}

for ER membrane integration

$\begin{array}{ll}\text { ERM protein complex } & \\ & - \text { EMC1 } \\ & - \text { EMC2 } \\ & - \text { EMC3 } \\ & - \text { EMC4 } \\ & - \text { EMC5 (MMGT1) } \\ & - \text { EMC6 (TMEM93) } \\ & - \text { EMC7 } \\ & - \text { EMC8 } \\ & - \text { EMC9 } \\ - & \text { EMC10 }\end{array}$

\begin{tabular}{|c|c|c|}
\hline \multicolumn{3}{|c|}{ \#TMCO1 complex $\S$} \\
\hline- & TMCO1 & 2013 \\
\hline- & Nicalin & 99 \\
\hline- & TMEM147 & 21 \\
\hline- & CCDC47 (Calumin) & 193 \\
\hline- & NOMO & 267 \\
\hline
\end{tabular}

PAT complex

- PAT10 (Asterix)

- CCDC47 (Calumin)

124

300

270

70

$35 \quad$ ERM

247

209

3

2013

99 ERM Glaucoma, Cerebrofaciothoracic

Dysplasia

267

193

ERM

for ER membrane integration plus translocation

\#Sec61 complex $\S$

- Sec61 61

ERM

- Sec61 $\beta$

139

456

- Sec61

400

\#Sec62 (TLOC1) 26

ER Chaperones

- Sec63 (ERj2)

- \#ERj1 (DNAJC1)

- $\operatorname{BiP}($ Grp78, HSPA5)

- Grp170 (HYOU1)

- Sil1 (BAP)

$26 \quad$ ERM

Diabetes ${ }^{5}, \mathrm{CVID}^{6}$, TKD, Neutropenia

PLD, Colorectal cancer GBM, Hepatocellular carcinoma

Breast-, Prostate-, Cervix-, Lung-cancer

\#Calnexin ${ }_{\text {palmitoylated }}$

\#TRAM1

TRAM2

\#TRAP complex

- TRAP $\alpha((\mathrm{SSR} 1)$

- TRAP $\beta$ (SSR2)

- TRAP $\gamma($ SSR3)

$168 \quad$ ERM

ERM

$\begin{array}{cc}8 & \text { ERM } \\ 8253 & \text { ERL }\end{array}$

ERL

923 ERL

149 ERL

$7278 \quad$ ERM

26 ERM

40 ERM

568

ERM

- $\quad$ TRAPס (SSR4)

1701

3212

CDG, Hepatocellular

Carcinoma

CDG 
Table 1. Cont.

\begin{tabular}{|c|c|c|c|}
\hline Component/Subunit for ER Targeting & Abundance ${ }^{1}$ & Localization $^{2}$ & Linked Diseases \\
\hline \multicolumn{4}{|l|}{ for covalent modification } \\
\hline \#Oligosaccharyltransferase (OST-A) & & ERM & \\
\hline - RibophorinI (Rpn1) & 1956 & & \\
\hline - RibophorinII (Rpn2) & 527 & & \\
\hline - OST48 & 273 & & CDG \\
\hline - Dad1 & 464 & & \\
\hline - OST4 & & & \\
\hline - $\quad$ TMEM258 & & & \\
\hline$-\quad \operatorname{Stt} 3 \mathrm{~A} *$ & 430 & & CDG \\
\hline$-\quad \mathrm{DC} 2$ & & & \\
\hline$-\quad$ Kсp2 & & & \\
\hline \multicolumn{4}{|l|}{ Oligosaccharyltransferase (OST-B) } \\
\hline - RibophorinI (Rpn1) & 1956 & & \\
\hline - RibophorinII (Rpn2) & 527 & & \\
\hline - OST48 & 273 & & CDG \\
\hline - Dad1 & 464 & & \\
\hline$-\quad$ OST4 & & & \\
\hline - $\quad$ TMEM258 & & & \\
\hline$-\quad \mathrm{Stt} 3 \mathrm{~B}^{*}$ & 150 & & CDG \\
\hline - TUSC3 & & & CDG \\
\hline - MagT1 & 33 & & \\
\hline Signal peptidase (SPC-A) & & \multirow[t]{5}{*}{ ERM } & \\
\hline$-\quad$ SPC12 & 2733 & & \\
\hline$-\quad \mathrm{SPC} 18 *(\mathrm{SEC} 11 \mathrm{~A})$ & & & \\
\hline$-\quad \mathrm{SPC} 22 / 23$ & 334 & & \\
\hline - SPC25 & 94 & & \\
\hline Signal peptidase (SPC-C) & & \multirow[t]{5}{*}{ ERM } & \\
\hline - SPC12 & 2733 & & \\
\hline$-\quad \mathrm{SPC} 21 *(\mathrm{SEC} 11 \mathrm{C})$ & & & \\
\hline$-\quad \mathrm{SPC} 22 / 23$ & 334 & & \\
\hline$-\quad$ SPC25 & 94 & & \\
\hline \multicolumn{4}{|l|}{ GPI transamidase (GPI-T) } \\
\hline - GPAA1 & 9 & \multirow{5}{*}{ ERM } & \\
\hline - $\quad$ PIG-K & 38 & & \\
\hline - PIG-S & 86 & & \\
\hline - PIG-T & 20 & & \\
\hline - $\quad$ PIG-U & 42 & & \\
\hline
\end{tabular}

${ }^{1}$ Abundance refers to the concentration (nM) of the respective protein in HeLa cells, as reported by Hein et al. [45]. ${ }^{2}$ Localization refers to the functional intracellular localization(s) of the respective protein [1-4,35,36,41], i.e., C, Cytosol, ERL, ER lumen, ERM, ER membrane, PexM, and Peroxisome membrane. ${ }^{3}$ Alternative protein names are given in parentheses. ${ }^{4}$ Complexes are indicated by italics. Abbreviations for the protein names: EMC, ER membrane (protein) complex; GET, guided entry of tail-anchored proteins; SEC, (protein involved in) secretion; SND, SRP-independent; SR, SRP receptor; SRP, signal recognition particle; SSR, signal sequence receptor; TMEM, transmembrane (protein); TRAM, translocating chain-associating membrane (protein); TRAP, translocon-associated protein; TRC, transmembrane recognition complex. ${ }^{5}$ Diabetes was linked to the particular protein in mice. ${ }^{6}$ Abbreviation for diseases: CDG, congenital disorder of glycosylation; CVID, common variable immunodeficiency; GBM, glioblastoma multiforme; HUS, hemolytic-uremic syndrome; MSS, Marinesco-Sjögren syndrome; PLD, polycystic liver disease; TKD, tubulointerstitial kidney disease, as reported by Sicking et al. [34]. \# indicates ribosome binding ability; ${ }^{\S}$ indicates ion channel activity; ${ }^{*}$ indicates enzymatically active subunit. 
a

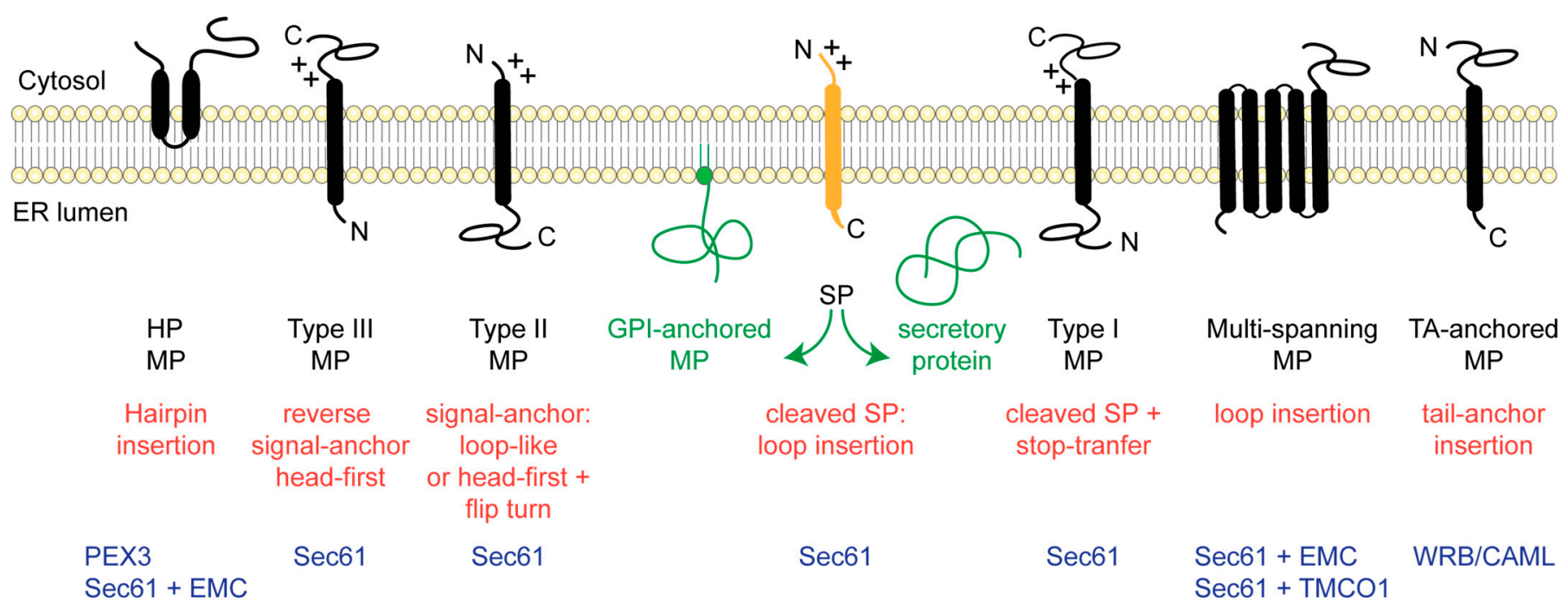

b
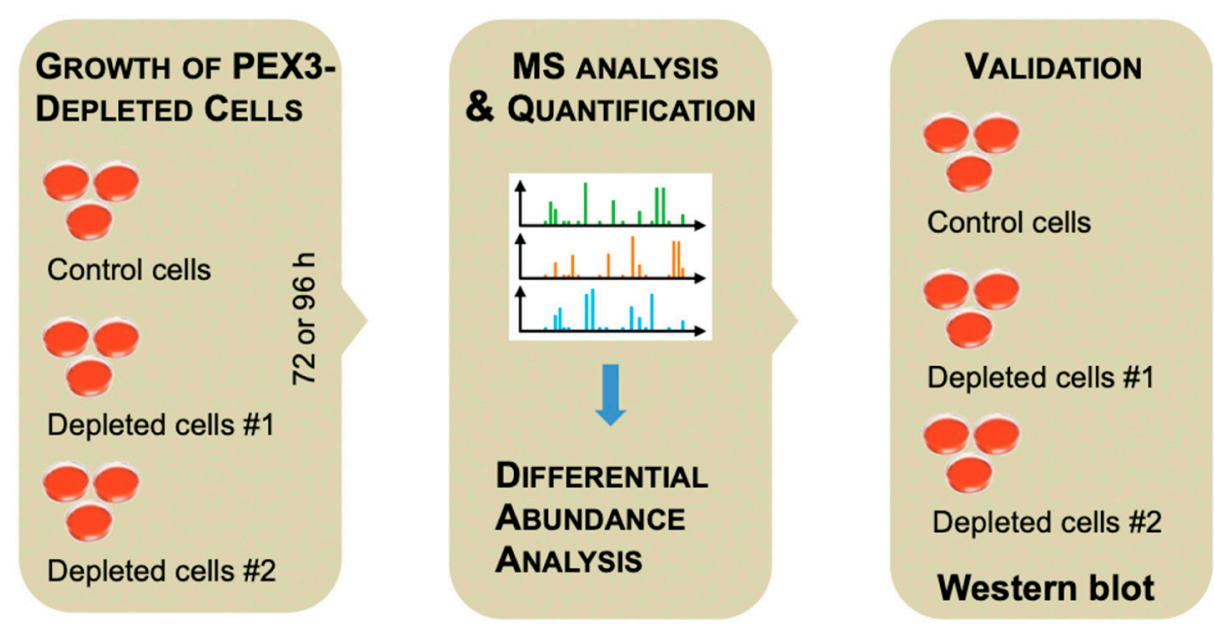

Figure 1. Types of ER membrane proteins and our experimental strategy to address their biogenesis. (a) The cartoon depicts a signal peptide (SP) (in yellow) and six types of ER membrane proteins (MP) (in black), together with their membrane protein type and the mechanism of membrane insertion (both indicated below the cartoon). Cleavable SPs (in yellow) can facilitate the ER import of secretory proteins (in green), glycosylphosphatidylinositol (GPI)-anchored membrane proteins (in green), and several types of membrane proteins, including single-spanning type I membrane proteins. Positively charged amino acid residues (+) play an important role in membrane protein and SP orientation, i.e., they typically follow the positive inside rule [14]. Amino-terminal transmembrane helices (TMHs) can serve as signal-anchor sequences to facilitate the membrane insertion of type II, type III, and many multi-spanning membrane proteins. In the case of membrane proteins with amino-terminal TMHs, membrane insertion typically involves the same components and mechanisms, which deliver secretory proteins (in green) and GPI-anchored membrane proteins (in green) to the ER lumen. The central component here is the Sec61 complex. In some cases, however, auxiliary membrane protein insertases, such as EMC or TMCO1 complex, play a role. These can also operate as stand-alone membrane protein insertases, an activity that they have in common with the WRB/CAML complex [4]. Hairpin (HP) proteins have a monotopic topology with N- and C-termini facing the cytosol, and some of them require PEX3 for membrane targeting. C, carboxy-terminus; N, amino-terminus. (b) The experimental strategy was as follows: siRNA-mediated gene silencing using two different siRNAs for each target and one non-targeting (control) siRNA, respectively, with three replicates for each siRNA for $96 \mathrm{~h}$, followed by the label-free quantitative analysis of the total cellular proteome, and then differential protein abundance analysis to identify negatively affected proteins (i.e., putative clients of the target) and positively affected proteins (i.e., putative compensatory mechanisms), and finally validation by Western blot. In addition, PEX3-deficient Zellweger patient cells were analyzed in triplicates. 


\section{Results}

2.1. Quantitative Proteomic Analysis of HeLa Cells after the Transient and Partial Depletion of PEX3 by siRNA

Our approach to the characterization of the client spectrum of PEX3 in ER protein targeting involves the gene silencing of the putative receptor PEX3 in HeLa Kyoto cells with two different targeting siRNAs in parallel to a non-targeting or control siRNA, and differential proteomic analysis by label-free quantitative MS analysis and differential protein abundance analysis (Figure $1 \mathrm{~b}$ ). This protocol was developed and previously used to characterize the client spectrum and client SP features of ER protein translocation components, including Sec61 complex (as a proof on concept), TRAP complex, Sec62/Sec63 complex, TRAM1-protein, ERj1, BiP, and the mRNA targeting components KTN1 and RRBP1 [33,46-48]. The approach is based on the assumption that polypeptide precursors, which have to be imported into the ER, are degraded by the proteasome in the cytosol upon interference with their ER targeting or translocation because their SPs or TMHs are not easily compatible with the aqueous character of the cytosol. Therefore, their cellular levels are decreased compared to those of the control cells, and this change is detected by quantitative MS and subsequent differential protein abundance analysis [46]. Typically, the decrease was observed to be accompanied by an increase of ubiquitin-conjugating enzymes [33,46-48]. Furthermore, a simultaneous increase in other ER import components was detected, which is consistent with the overlap of pathways and, additionally, may indicate a genetic interaction between different pathways and cellular compensation.

Here, we applied the established experimental strategy to identify precursor polypeptides that may depend on PEX3-dependent targeting to the ER [46]. They were expected among the negatively affected proteins in the label-free quantitative MS and subsequent differential protein abundance analysis. HeLa cells were treated in triplicates with two different PEX3-targeting siRNAs (PEX3 \#1 siRNA, PEX3 \#2 siRNA) in parallel to a non-targeting (control) siRNA for $96 \mathrm{~h}$. Each MS experiment provided proteome-wide abundance data as LFQ intensities for three sample groups: one control (non-targeting siRNA treated) and two stimuli (down-regulation by two different targeting siRNAs directed against the same gene), which each having three data points (Figure 1b). In order to identify which proteins were affected by knock-down in siRNA-treated cells relative to the non-targeting (control) siRNA treated sample, we log2-transformed the ratio between the siRNA and control siRNA samples, and performed two separate unpaired $t$-tests for each siRNA against the control siRNA sample according to [46]. The $p$ values obtained by the unpaired $t$-tests were corrected for multiple testing using a permutation-based false discovery rate (FDR) test. The proteins with an FDR-adjusted $p$ value of below $5 \%$ were considered significantly affected by the knock-down of the targeted protein.

After PEX3 depletion, 6488 different proteins were quantitatively detected by MS in all of the samples (Figure S1, Tables 2, S1 and S2). The MS data were deposited to the ProteomeXchange Consortium via the PRIDE partner repository [49] with the dataset identifier PXD012005 (http: / / www.proteomexchange.org; last accessed on 2 May 2021). They included the expected representations of proteins with cleaved SP (7\%), N-glycosylated proteins $(9 \%)$, and membrane proteins $(13 \%)$, which were comparable to the previously published Sec61 and TRAP experiments (Figure S1c, left small pies) [46]. Through the application of the established statistical analysis, we found that transient PEX3 depletion significantly affected the steady-state levels of 13 proteins: 13 negatively and none positively (with a permutation-based false discovery rate-adjusted $p$ value $<0.05$ ). As had to be expected, PEX3 itself was negatively affected (Figure S1a, volcano plots), which was confirmed by Western blot analysis (Figure S1b). The identified precursors included one protein with cleavable SP (the ER membrane protein AGPAT1), and two membrane proteins with TMH (not counting PEX3), i.e., the endo- and lysosomal membrane protein TMEM192 with four transmembrane domains, and the single-pass type II plasma membrane protein SGCD (Figure S1b, Table S2). Of these three negatively affected proteins, one was N-glycosylated (SGCD). There were no proteins with an annotated functional location 
in peroxisomes or LDs among the negatively affected proteins. There was no positively affected protein observed. These results raise the question of why PEX3 depletion from HeLa cells had hardly any effect on the cellular proteome. There are several possibilities. The simplest answer would be that the depletion efficiency of $85 \%$ may not have been high enough to cause the accumulation of precursor proteins. Another answer could be that PEX3 function in ER protein import in HeLa cells is not essential, i.e., it can be substituted by other proteins or pathways. Another possibility is that the accumulating precursors were not degraded but aggregated in the cytosol, or ended up in other organelles, where they were protected from degradation. These possibilities will we considered in further detail in the discussion.

Table 2. Statistics for the identification of putative PEX3 clients in comparison to the previously identified clients for ER membrane targeting and translocation components.

\begin{tabular}{|c|c|c|c|c|c|c|c|}
\hline Proteins & PEX3 & $\mathrm{Z}^{1}$ & RRBP1 $^{2}$ & $\mathrm{KTN1}^{2}$ & SEC61 $^{2}$ & TRAP $^{2}$ & $\mathrm{CDG}^{1,2}$ \\
\hline Quantified proteins & 8178 & 6328 & 4813 & 4947 & 7212 & 7670 & 5920 \\
\hline \multirow{2}{*}{$\begin{array}{l}\text { Statistically analyzed proteins } \\
\text { representing the secretory pathway (\%) }\end{array}$} & 6488 & 6328 & 4813 & 4947 & 5129 & 5911 & 5920 \\
\hline & 29 & 29 & 26 & 27 & 26 & 27 & 36 \\
\hline Proteins with SP $(\%)$ & 7 & 7 & 6 & 6 & 6 & 7 & nd $^{3}$ \\
\hline N-Glycoproteins (\%) & 9 & 9 & 8 & 8 & 8 & 8 & nd \\
\hline Membrane proteins (\%) & 13 & 13 & 12 & 13 & 12 & 13 & nd \\
\hline Positively affected proteins & 0 & 97 & 157 & 25 & 342 & 77 & 39 \\
\hline \multirow{2}{*}{$\begin{array}{l}\text { Negatively affected proteins } \\
\text { representing the secretory pathway (\%) }\end{array}$} & 13 & 141 & 141 & 45 & 482 & 180 & 279 \\
\hline & 54 & 39 & 37 & 41 & 61 & 40 & 36 \\
\hline Negatively affected proteins with SP (\%) & 8 & 19 & 18 & 7 & 41 & 22 & 12 \\
\hline Negatively affected N-glycoproteins (\%) & 8 & 21 & 17 & 18 & 45 & 23 & 17 \\
\hline Negatively affected membrane proteins (\%) & 31 & 18 & 18 & 22 & 36 & 26 & 23 \\
\hline \multirow{5}{*}{$\begin{array}{l}\text { Negatively affected proteins with SP } \\
\text { including N-glycoproteins } \\
\text { corresponding to } \% \\
\text { including membrane proteins } \\
\text { corresponding to } \%\end{array}$} & 1 & 27 & 21 & 3 & 197 & 38 & 34 \\
\hline & 0 & 23 & 16 & 3 & 158 & 28 & 30 \\
\hline & 0 & 85 & 76 & 100 & 80 & 74 & 88 \\
\hline & 1 & 6 & 6 & 1 & 77 & 19 & 16 \\
\hline & 100 & 22 & 29 & 33 & 39 & 50 & 53 \\
\hline \multirow{3}{*}{$\begin{array}{l}\text { Negatively affected proteins with TMH } \\
\text { including N-glycoproteins } \\
\text { corresponding to \% }\end{array}$} & 3 & 16 & 18 & 8 & 98 & 22 & 41 \\
\hline & 1 & 6 & 7 & 4 & 56 & 11 & 17 \\
\hline & 33 & 38 & 39 & 50 & 57 & 50 & 41 \\
\hline \multirow{4}{*}{$\begin{array}{l}\text { Negatively affected peroxisomal proteins } \\
\text { corresponding to } \% \\
\text { including membrane proteins } \\
\text { corresponding to } \%\end{array}$} & 1 & 12 & 0 & 1 & 1 & 0 & 1 \\
\hline & 8 & 9 & nd & 2 & 0 & nd & 0 \\
\hline & 1 & 6 & nd & 0 & 1 & 0 & 1 \\
\hline & 100 & 50 & nd & nd & 100 & nd & 100 \\
\hline \multirow{4}{*}{$\begin{array}{l}\text { Negatively affected mitochondrial proteins } \\
\text { corresponding to } \% \\
\text { including membrane proteins } \\
\text { corresponding to } \%\end{array}$} & 0 & 14 & 6 & 1 & 29 & 14 & 21 \\
\hline & nd & 10 & 4 & 2 & 1 & 1 & 1 \\
\hline & nd & 4 & 3 & 0 & 11 & 3 & 8 \\
\hline & nd & 29 & 50 & nd & 38 & 21 & 38 \\
\hline
\end{tabular}

${ }^{1} \mathrm{Z}$ and CDG refer to immortalized fibroblasts from patients suffering from Zellweger syndrome or a congenital disorder of glycosylation.

${ }^{2}$ Refers to siRNA-mediated knockdown HeLa cells, and was previously published $[33,46] .{ }^{3}$ nd, not determined.

\subsection{Quantitative Proteomic Analysis of PEX3-Deficient Zellweger Patient Fibroblasts}

In the course of our previous analysis of Sec62- and Sec63 clients, we moved from the respective siRNA-treated and incompletely depleted HeLa cells with low client numbers on to CRISPR/Cas9-treated and deficient HEK293 cells, and indeed, we identified many more clients [47]. Therefore, we sought to test whether a complete PEX3 knockout in cells leads to the depletion of putative PEX3 client proteins. Therefore, we subjected control fibroblasts and immortalized Zellweger patient fibroblasts with PEX3 deficiency [41], which had been grown in triplicates, to label-free quantitative proteomic analysis and differential protein abundance analysis, and analyzed the data for negatively affected proteins, i.e., potential PEX3 clients (Figure 2, Tables 2, S3-S5). The MS data were deposited to the ProteomeXchange Consortium via the PRIDE partner repository [49] with the dataset identifier PXD012005 (http:/ / www.proteomexchange.org; last accessed on 2 May 2021). 


\section{PEX3-deficient Zellweger patient fibroblasts}

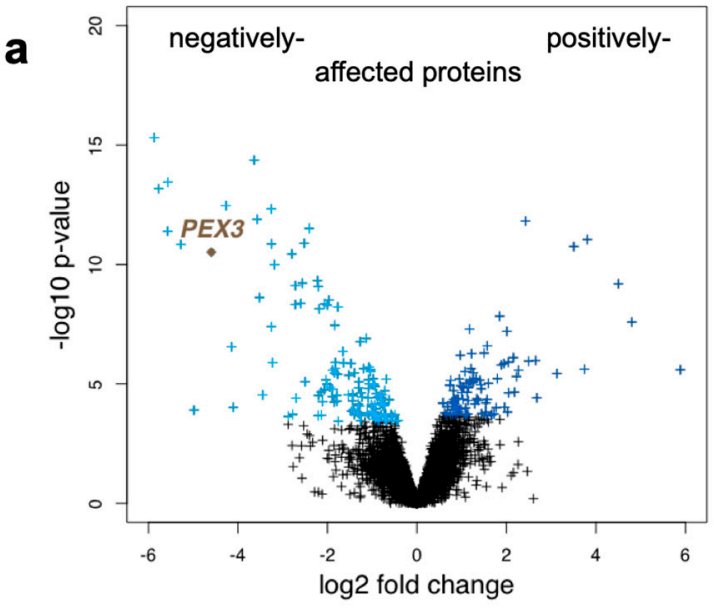

$\log 2$ fold change for PEX3: -4.59

\author{
Negatively affected proteins, \\ i.e. putative PEX3 substrates \\ with SP:
}

CCDC80, CDCP1, COL1A1, COL6A1, COL6A2,

COL6A3, COL11A1, CTHRC1, CTSB, DHRSX,

ENP44, FBLN1, FKBP7, HLA-C, HTRA1,

ICAM1, ITGB5, LAMA4, LEPREL1, LOX,

LRRC15, MFGE8, PCOLCE, PCSK9,

PDIA5, PLOD2, PRSS23,

with TMH:

AIFM2, COLEC12, CYBRD1, DHRS7B, ENPP1, ERMP1, MAN1A1, TMEM237, TMUB2, TOR1AIP1 with tail anchor:

CCDC136, STX6, VAMP3 with hair pin(s):

ATL1, RTN3

of peroxisomal membranes:

ABCD3, ACBD5, AGPS, FAR1, PEX13, PXMP2

Notably, the proteins in red were also negatively affected by PEX3 depletion

in HeLa cells but did not meet the stringent significance theshold.
C

$\alpha$ Tubulin

\begin{tabular}{|c|c|c|c|}
\hline PEX3 +/+ & & & $E$ \\
\hline 12 & 3 & 1 & \\
\hline
\end{tabular}

fibroblasts sample b PEX3 $-\infty$

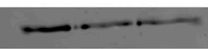

\section{Negatively affected proteome}
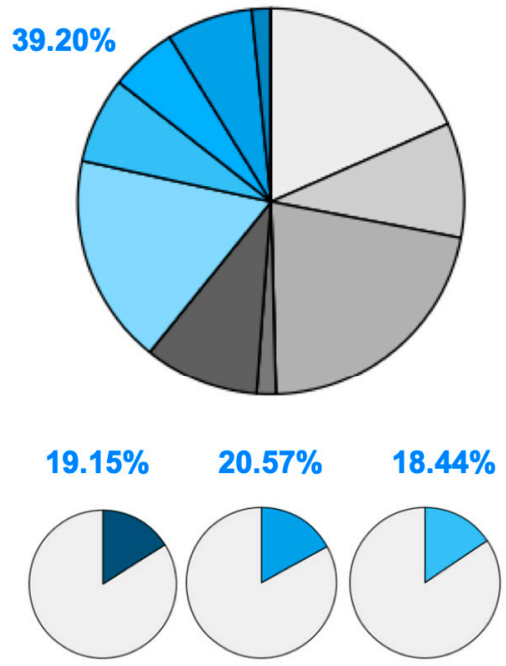

$\square$ nucleus

mitochondrion

$\square$ cytosol

$\square$ ribosome

$\square$ cytoskeleton

$\square$ peroxisome

$\square$ plasma membrane

$\square$ ER

$\square$ golgi

$\square$ extracellular

$\square$ lysosome

endosome

vacuole

signal peptide

$\square \mathrm{N}$-glycosylated protein

$\square$ membrane protein

Figure 2. Volcano plots and Gene Ontology (GO) enrichment for PEX3-deficient Zellweger patient fibroblasts. (a) The differentially affected proteins were characterized by the mean difference of their intensities plotted against the respective permutation-based false discovery rate-adjusted $p$-values in the volcano plots; PEX3 is highlighted. In addition, the proteins, which were negatively affected by PEX3 deficiency are given in the right panel. (b) PEX3 deficiency was evaluated by Western blot. The molecular mass values are indicated in kilodaltons (KDa). Only the area of interest of the blot is shown; the original images are shown in the Supplementary Materials. (c) The classification of the putative PEX3 clients was based on GO enrichment factors where the results from the complete set of quantified proteins in the left panel are compared with the negatively affected proteome. The protein annotations of the SPs, membrane location, and N-glycosylation in humans were extracted from UniProtKB, and were used to determine the enrichment of the GO annotations among the negatively affected proteins. 
We quantitatively identified a total of 6328 different proteins by MS, 141 of which were negatively affected by PEX3 deficiency in the patient fibroblasts versus the control fibroblasts. As had to be expected, PEX3 itself was negatively affected (Figure 2a, volcano plots), which was confirmed by Western blot (Figure 2b). Applying the established statistical analysis, we found that PEX3 deficiency significantly affected the steady-state levels of 238 proteins: 141 negatively and 97 positively (permutation-based false discovery rate-adjusted $p$ value $<0.05$ ). Of the negatively affected proteins, GO terms assigned 39.2\% to organelles of the endocytic and exocytic pathways (Figure 2c, large pies), which corresponds to a 1.36-fold enrichment (Figure 2c, large pies, 39.2\% divided by $28.91 \%=1.36$ ) and is below the average values of 1.46 and 1.94 observed after the depletion of the mRNA targeting components KTN1 (1.55) and RRBP1 (1.37), and the translocation components Sec61 (2.37) and TRAP (1.5), respectively (Table 2) [33,46]. In contrast to the PEX3-knockdown cells (Figure S1c), we also detected the enrichment of proteins with SP (2.65-fold), $\mathrm{N}$-glycosylated proteins (2.2-fold), and membrane proteins (1.36-fold) (Figure 2c, small pies), which was lower compared to the Sec61 $(6.51,2.83,2.51)$ and TRAP experiments $(3.3$, $2.7,2.1)$, but higher compared to the $\operatorname{KTN} 1(1,2.09,1.76)$ and RRBP1 experiments $(2.44$, $2.12,1.46)[33,46]$.

The negatively affected proteins of the secretory pathway included 27 proteins with cleavable SP (including six collagens or collagen-like proteins, three collagen-modifying proteins, three ER lumenal proteins-i.e., FKBP7, PCSK9, and PDIA5-the lysosomal cathepsin CTSB, eight secretory proteins, the ER membrane protein PLOD2, and the plasma membrane proteins ENPP4, HLA-C, ICAM1, ITGB5, and LRRC15 (Figure 2a).

Furthermore, 15 membrane proteins of the secretory pathway with TMH (not counting PEX3) were negatively affected, i.e., most notably the two ER-resident hairpin proteins ATL1 and RTN3; the three tail-anchored proteins CCDC136, STX6 and VAMP3; the ER membrane proteins DHRS7B, ERMP1, and TMUB2; the Golgi protein MAN1A1; the plasma membrane proteins AIFM2 (which has additional locations, see below), COLEC12, CYBRD1, ENPP1, and TMEM237; and the nuclear envelope protein TOR1AIP1 (Figure 2a, Tables 3 and S4). Of these 42 negatively affected proteins, 29 were N-glycosylated proteins (23 with SP and 6 with TMH).

Interestingly, there were 14 precursors of mitochondrial proteins negatively affected by PEX3 deficiency (Table S4), a phenomenon previously observed after the depletion of RRBP1 from HeLa cells and attributed to their physiological trafficking from the ER to mitochondria via the newly identified ER-SURF pathway [11,33]. Among these negatively affected mitochondrial proteins were three outer membrane proteins (AIFM2, RHOT1, VAT1), one inner membrane protein (NDUFV3), and ten matrix proteins, two of which had a dual localization in the mitochondria and peroxisomes (ACAD11, SCP2). Alternatively, our observation of mitochondrial proteins among the negatively affected ones may be due to the findings that PEX19, at least, associates with peroxisomes and mitochondria, and, for example, facilitates the protein biogenesis of the tail-anchored membrane proteins Fis1 and Gem1 for both organelles [50].

The positively affected proteins in the PEX3-deficient fibroblasts included cell adhesion molecules (such as ITGA1, L1CAM, and NCAM1), signal transduction components of the plasma membrane (ANXA3, PKD2), mitochondrial membrane proteins of the inner membrane with functions in protein import into the mitochondria (DNAJC15) or protein quality control (OMA1), and the cytosolic chaperone HSPB6.

2.3. Negatively Affected Precursor Proteins in Zellweger Patient Fibroblasts Are Specific for PEX3Deficiency, and Are Partially Affected in PEX3-Depleted HeLa Cells

In order to validate the proteomic data on putative PEX3-substrates, we conducted independent Western blot experiments with the PEX3-deficient Zellweger and control fibroblasts for the SP-containing candidate PDIA5, the hairpin protein RTN3, the dual topology LD/peroxisome protein Far1, and the peroxisomal protein ACBD5 (Figure 3). All of these proteins were depleted in PEX3-deficient fibroblasts, fully confirming the proteomic analysis and verifying them as putative PEX3 clients. Interestingly, for RTN3, 
we observed that specifically the $100 \mathrm{kDa}$ isoform was depleted in the PEX3-deficient cells, while the $25 \mathrm{kDa}$ isoform remained largely unaltered (Figure 3, e versus f).

For PEX3-depleted HeLa cells, we observed that 17 of the 48 negative hits were not quantified, and that 18 out of 31 putative PEX3 clients in Zellweger patient fibroblasts (i.e., 58\%) were also negatively affected by PEX3 depletion in HeLa cells (including two out of three tail-anchored proteins, one out of two hairpin proteins, and four out of six peroxisomal proteins), but did not meet the stringent significance threshold (Table S6 and proteins indicated in red in Figure 2). Notably, the PEX3 depletion in the HeLa cells was not as efficient as it was in the fibroblasts (log2-fold change: -3.5 versus -4.6) (Figures 2 and S1). Hence, it is understandable that the levels of the putative PEX3 clients are less perturbed in HeLa cells than in fibroblasts. Still, the majority of them (18 versus 13) are perturbed in the same negative direction as they are in fibroblasts (Table S1).

We consider these putative clients of PEX3 for organelles of the secretory pathway to be specific for additional reasons. First, the negatively affected proteins included, as expected, twelve precursors of proteins with a functional location in peroxisomes (not counting PEX3), including six peroxisomal membrane proteins (Figure 2a) (Table 3). The peroxisomal membrane proteins were ABCD3, ACBD5, AGPS, FAR1, PEX13, and PXMP2. Notably, the tail-anchored membrane protein FAR1 exhibits a dual topology, and can locate to peroxisomes as well as to LDs [51]. Second, with two hairpin proteins, ATL1 and RTN3, among the negatively affected proteins, we also confirmed a second class of already-known PEX3 clients in human cells under physiological conditions (Table 3). Third, only one of the negatively affected peroxisomal proteins, PEX13, had previously been observed for TRAP-deficient fibroblasts from patients who suffer from congenital disorders of glycosylation (CDG) and are either SSR3- (coding for TRAP $\gamma$ ) or SSR4 (TRAP8)deficient [46]. Furthermore, there was no overlap in the positively affected proteins that accumulate in either CDG or Zellweger patient fibroblasts.

Table 3. Negatively affected proteins in PEX3-deficient cells, i.e., putative PEX3 substrates.

\begin{tabular}{|c|c|c|c|}
\hline Gene & Subcellular Location & Membrane Protein Type & SS or TMH \\
\hline ACBD5 & Peroxisome membrane & Single-spanning membrane protein & \\
\hline COLEC12 & Membrane & Single-spanning type II membrane protein & $\mathrm{TMH}$ \\
\hline LRRC15 & Membrane & Single-spanning type I membrane protein & SP \\
\hline PEX3 & Peroxisome membrane & Single-spanning membrane protein & \\
\hline TOR1AIP1 & Nuclear envelope inner membrane & Single-spanning membrane protein & $\mathrm{TMH}$ \\
\hline COL1A1 & Secreted, Extracellular space, Extracellular matrix & & SP \\
\hline AGPS & Peroxisome membrane & & \\
\hline ACAD11 & Peroxisome, Mitochondrion & & \\
\hline STX6 & Golgi apparatus membrane & Tail-anchored membrane protein & tail anchor \\
\hline CCDC136 & Acrosome membrane, Secretory vesicle, Cytoplasmic vesicle & Tail-anchored membrane protein & tail anchor \\
\hline FAR1 & Peroxisome membrane & Tail-anchored membrane protein & tail anchor \\
\hline PXMP2 & Peroxisome membrane & Multi-spanning membrane protein & \\
\hline ATL1 & Cell projection, Golgi apparatus membrane, ER membrane, & Hairpin membrane protein with one HP & hairpin \\
\hline COL6A2 & Extracellular matrix, Membrane, Secreted, Extracellular space & & SP \\
\hline LOX & Extracellular space, Secreted & & SP \\
\hline ERMP1 & ER membrane & Multi-spanning membrane protein & $\mathrm{TMH}$ \\
\hline CYBRD1 & Membrane & Multi-spanning membrane protein & $\mathrm{TMH}$ \\
\hline TMUB2 & Membrane & Multi-spanning membrane protein & TMH \\
\hline ABCD3 & Peroxisome membrane & Multi-spanning membrane protein & \\
\hline SCP2 & Peroxisome, Mitochondrion, Cytoplasm & & \\
\hline $\mathrm{CDCP} 1$ & Secreted, Cell membrane & & SP \\
\hline COL6A3 & Extracellular space, Secreted, Extracellular matrix & & SP \\
\hline
\end{tabular}


Table 3. Cont

\begin{tabular}{|c|c|c|c|}
\hline Gene & Subcellular Location & Membrane Protein Type & SS or TMH \\
\hline TMEM237 & Cell projection, Membrane, Cilium & Multi-spanning membrane protein & TMH \\
\hline ENPP4 & Cell membrane & Single-spanning type I membrane protein & SP \\
\hline HTRA1 & Cell membrane, Secreted, Cytoplasm, Cytosol & & SP \\
\hline VAMP3 & Synapse, Membrane, Cell junction, Synaptosome & Tail-anchored membrane protein & tail anchor \\
\hline MFGE8 & Membrane, Secreted & & SP \\
\hline PRSS23 & Secreted & & SP \\
\hline DHRS4 & Peroxisome, Nucleus & & \\
\hline ITGB5 & Membrane & Single-pass type I membrane protein & SP \\
\hline FBLN1 & Extracellular space, Secreted, Extracellular matrix & & SP \\
\hline COL6A1 & Extracellular space, Secreted, Extracellular matrix & & SP \\
\hline PCSK9 & Endosome, Golgi apparatus, Cell surface, Secreted, ER, Lysosome & & SP \\
\hline CTHRC1 & Extracellular space, Secreted, Extracellular matrix & & SP \\
\hline DHRSX & Secreted & & SP \\
\hline HLA-C & Membrane & Single-spanning type I membrane protein & SP \\
\hline CCDC80 & Secreted, Extracellular space, Extracellular matrix & & SP \\
\hline RTN3 & ER membrane, Golgi apparatus membrane & Hairpin membrane protein with two HP & hairpin \\
\hline ENPP1 & Secreted, Basolateral cell membrane, Cell membrane & Single-spanning type II membrane protein & TMH \\
\hline PLOD2 & Rough ER membrane & & SP \\
\hline RHOT1 & Mitochondrion outer membrane & & \\
\hline COL11A1 & Extracellular matrix, Extracellular space, Secreted & & SP \\
\hline NDUFV3 & Mitochondrion inner membrane & & \\
\hline PCOLCE & Secreted & & SP \\
\hline AIFM2 & Membrane, Mitochondrion outer membrane, Lipid droplet & Single-spanning membrane protein & TMH \\
\hline MAN1A1 & Golgi apparatus membrane & Single-spanning type II membrane protein & TMH \\
\hline ACBD7 & Cytosol & & \\
\hline ICAM1 & Membrane & Single-spanning type I membrane protein & SP \\
\hline CTSB & Lysosome, Melanosome, Secreted, Extracellular space & & SP \\
\hline DHRS7B & ER membrane & Single-spanning type II membrane protein & TMH \\
\hline LAMA4 & Extracellular matrix, Extracellular space, Secreted & & SP \\
\hline LEPREL1 & ER, Golgi apparatus & & SP \\
\hline PEX13 & Peroxisome membrane & Single-spanning membrane protein & \\
\hline PDIA5 & ER lumen & & SP \\
\hline CTHRC1 & Extracellular space, Secreted, Extracellular matrix & & \\
\hline FKBP7 & ER lumen & & $\mathrm{SP}$ \\
\hline
\end{tabular}

The proteins are listed according to the decreasing negative effects of PEX3 depletion. The colors refer to peroxisomal proteins (yellow), mitochondrial proteins (brown), and proteins of the secretory pathway with SP, TMH, tail anchors (green) or hairpins (orange). As compared to Table S4, the GO annotation for TOR1AIP1, the hairpin of RTN3, and the definitions of the membrane protein types were taken from GeneCards (https: / / www.genecards.org; last accessed on 1 September 2021). In addition, the term "TMH" is used here only for proteins of the secretory pathway. Red letters refer to incomplete annotations (see text for details). HP, hairpin.

As outlined in Table 2, and for comparison with the PEX3-deficient Zellweger patient fibroblasts, 5919 different proteins were previously quantified for CDG patient fibroblasts, 279 of which were negatively affected by TRAP absence, and 39 of which were positively affected. In total, 100 of the negatively affected proteins were assigned to the secretory pathway, including 34 precursor polypeptides with SP and 41 with TMH (including the subunits of the heterotetrameric TRAP complex) [46]. A total of 47 of the negatively affected proteins were $\mathrm{N}$-glycoproteins ( 30 with SP and 17 with $\mathrm{TMH}$ ). The peroxisomal membrane protein PEX13 was among the negatively affected proteins, which was also negatively affected in PEX3-deficient Zellweger patient fibroblasts (Table 2). 

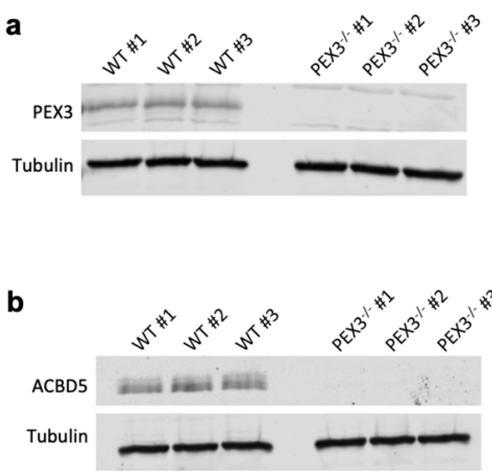

c

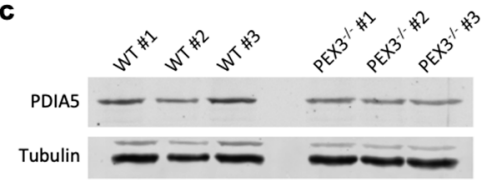

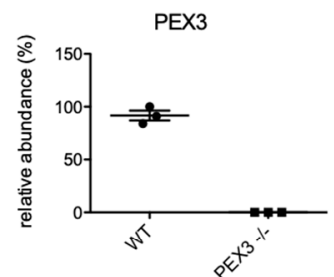

ACBD5
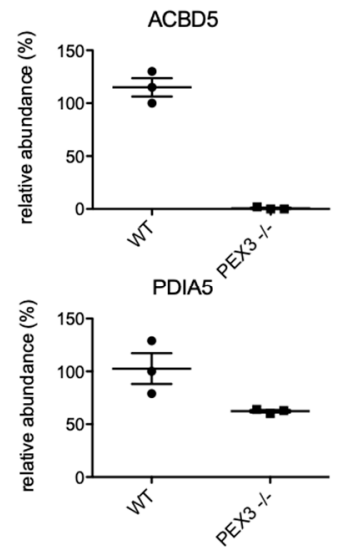

d

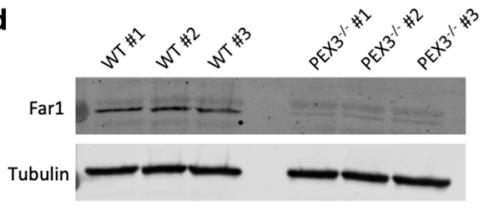

e

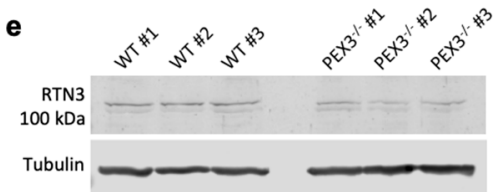

f

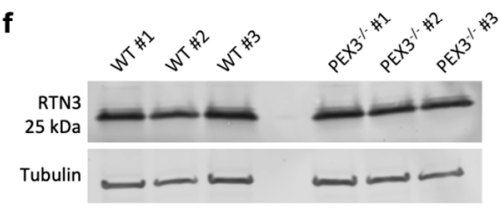

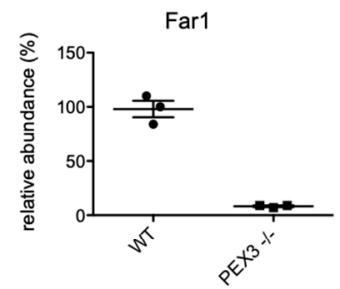

$\operatorname{Rtn} 3(100 \mathrm{kDa})$
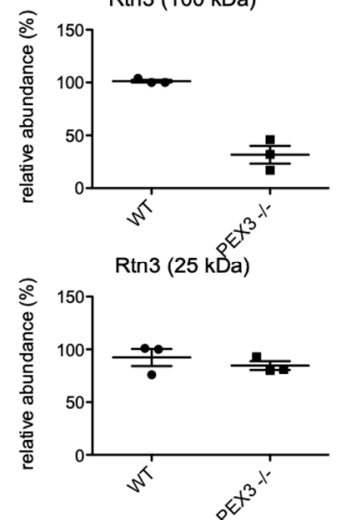

Figure 3. Validation of the PEX3 clients by Western blot analyses. (a-f) Three independent cell lysates from the control (WT) and PEX3-deficient fibroblasts (PEX3 ${ }^{-/-}$), respectively, were analyzed by Westen blotting using antibodies as indicated. Left panels: Relevant sections of the representative Western blots are shown; tubulin served as a loading control. We note that the full scans of all of the blots are shown in the supplement. Right panels: The scatter plots indicate the relative protein abundances in the control and PEX3-deficient fibroblasts, as derived from quantitative Western blots, as shown in the left panels. The signals were quantified by densitometry, and the relative abundances were calculated as the ratio of the signal of interest to the corresponding tubulin signal in the same lane, and were normalized against one control sample. The mean values with SEM from three independent lysates per cell line are indicated, as well as the individual data points for each replicate.

\section{Discussion}

Here, we addressed the question of which precursor polypeptides employ the PEX3dependent pathway for the targeting of or insertion and translocation, respectively, into the ER of human cells. First, we employed our previously established approach of the siRNA-mediated depletion of PEX3 in HeLa cells, the label-free quantitative MS of the total cellular proteome, and differential protein abundance analysis. Next, we quantified the negatively and positively affected proteins under conditions of PEX3 deficiency in Zellweger patient fibroblasts.

On first sight, the result of the siRNA-mediated depletion of PEX3 in HeLa cells was not very informative (Figure S1). In addition to the depletion of PEX3, only three precursor polypeptides with SP or TMH were found among the negatively affected proteins and may be considered as PEX3 clients in ER protein targeting. Notably, the one with an SP, AGPAT1, is an important enzyme in lipid metabolism, and is required for the synthesis of phosphatidic acid and triacylglycerides [52]. Therefore, it may affect LD biogenesis, and LD localization would not be unexpected. The proteins with a TMH are the endoand lysosomal membrane protein TMEM192 with four transmembrane domains, and the single-spanning type II plasma membrane protein SGCD. There was no peroxisomal protein negatively affected by PEX3 depletion, which has to be interpreted in light of the facts that PEX19 and PEX3 are essential for peroxisome formation $[37,38]$, and that PEX3 deficiency causes the complete absence of peroxisomes [42-44]. Together, these results raise the question of why PEX3 depletion from HeLa cells had hardly any effect on the cellular proteome. There are several possibilities. (i) The simplest answer would be that the depletion efficiency and its duration may not have been sufficient to cause a significant accumulation of precursor proteins. According to the MS data, the log2 
fold change was -3.4942 , i.e., the depletion efficiency was higher than $90 \%$, which is consistent with the Western blot analysis (Figure S1b). This residual amount of PEX3, however, may have been sufficient for physiological functions, and could explain the absence of an effect on peroxisomal proteins. (ii) Another answer may be that the PEX3 function in ER protein import in HeLa cells is not essential, i.e., it may also be provided by other proteins or pathways. Indeed, it was shown in cell-free ER protein import studies that certain peroxisomal membrane proteins can be targeted to the mammalian ER by SRP or TRC40 (including PEX3) [29,35,53-55]. Furthermore, some collagens, as well as some hairpin membrane proteins, were previously observed as RRBP1 clients (ATL2, ATL3, COL1A1, COL1A2, COL4A2) and SRP clients (ARL6IP1, RTN3), respectively, in cell biological or proteomic experiments $[30,33,35]$. (iii) Another possibility is that some accumulating precursors were not degraded, and either stayed soluble in the cytosol (as is known for catalase), aggregated, or ended up in other organelles (as is known for PEX14) [41], where they were protected from degradation. Indeed, we have previously observed the mis-targeting of certain precursors of secretory proteins into mitochondria in the absence of Sec61 function in HeLa cells [56]. Furthermore, the known PEX3 client, UBXD8, accumulates in mitochondria when PEX3 function is compromised [36]. (iv) Last but not least, all three possibilities may have contributed to the result we obtained in HeLa cells upon siRNA-mediated knockdown; we consider this the most likely explanation.

Under conditions of PEX3 deficiency in Zellweger patient fibroblasts, the results were more informative (Figure 2). First, the negatively affected proteins included twelve precursors of proteins with a functional location on or in peroxisomes, including six peroxisomal membrane proteins (Figure 4, Table 3). This was expected, and demonstrated once more the feasibility of the approach. However, this does not mean that all of these precursors of peroxisomal proteins are targeted to the ER. Rather, at least for the peroxisomal matrix proteins, it must be due to the complete absence of peroxisomes from the patient fibroblasts with PEX3 deficiency [42-44]. Likewise, we cannot rule out that the depletion of some precursors could derive from transcriptional effects. However, we consider this unlikely, as previous transcriptomics studies revealed that solely the absence of peroxisomes does not generally result in global mRNA expression changes [57].

Second, the identified precursors included the two ER-resident hairpin proteins ATL1 (with one hairpin) and RTN3 (with two hairpins), which is consistent with the previous finding that PEX3 is involved in the ER targeting of hairpin proteins $[35,36]$. It remains to be tested whether PEX3, possibly in cooperation with PEX16 [41], also facilitates the membrane insertion of these hairpin proteins, and whether additional membrane protein insertases-such as Sec61, EMC, TMCO1, and WRB/CAML-contribute to membrane insertion. Likewise, it is also conceivable that the members from the DHRS- and ACBDprotein families (ACBD5, DHRS4, DHRS7b, and DHRSX; Figure 2, Table 3) are first inserted into the ER membrane by PEX3 and additional insertion components of the ER. This will also have to be addressed in future research.

Furthermore, $14 \alpha$-helical membrane proteins, including four tail-anchored membrane proteins (CCDC136, FAR1, STX6 and VAMP3) and ten others (not counting PEX3)-i.e., DHRS7B (type II), ERMP1 (multi-pass), TMUB2 (multi-pass), MAN1A1 (type II), AIFM2, COLEC12 (type II), CYBRD1 (multi-pass), ENPP1 (type II), TOR1AIP1 (single-pass), and TMEM237 (multi-pass) - were negatively affected by PEX3 absence, and therefore can be considered as potential PEX3 clients in ER protein targeting (Table 3). Importantly, the annotated membrane topology of these potential clients should be considered with care, as they may be, in certain cases, incomplete. For example, it was recently shown that the tailanchored membrane protein FAR1 exhibits a dual topology, including a monotopic hairpin topology, and can therefore locate to peroxisomes as well as LDs [51]. Because ERMP1, STX6, and TOR1AIP1 were previously found to depend on Sec61 for their membrane insertion in HeLa cells, it is tempting to speculate that PEX3 is able to target precursors to the Sec61 complex. 


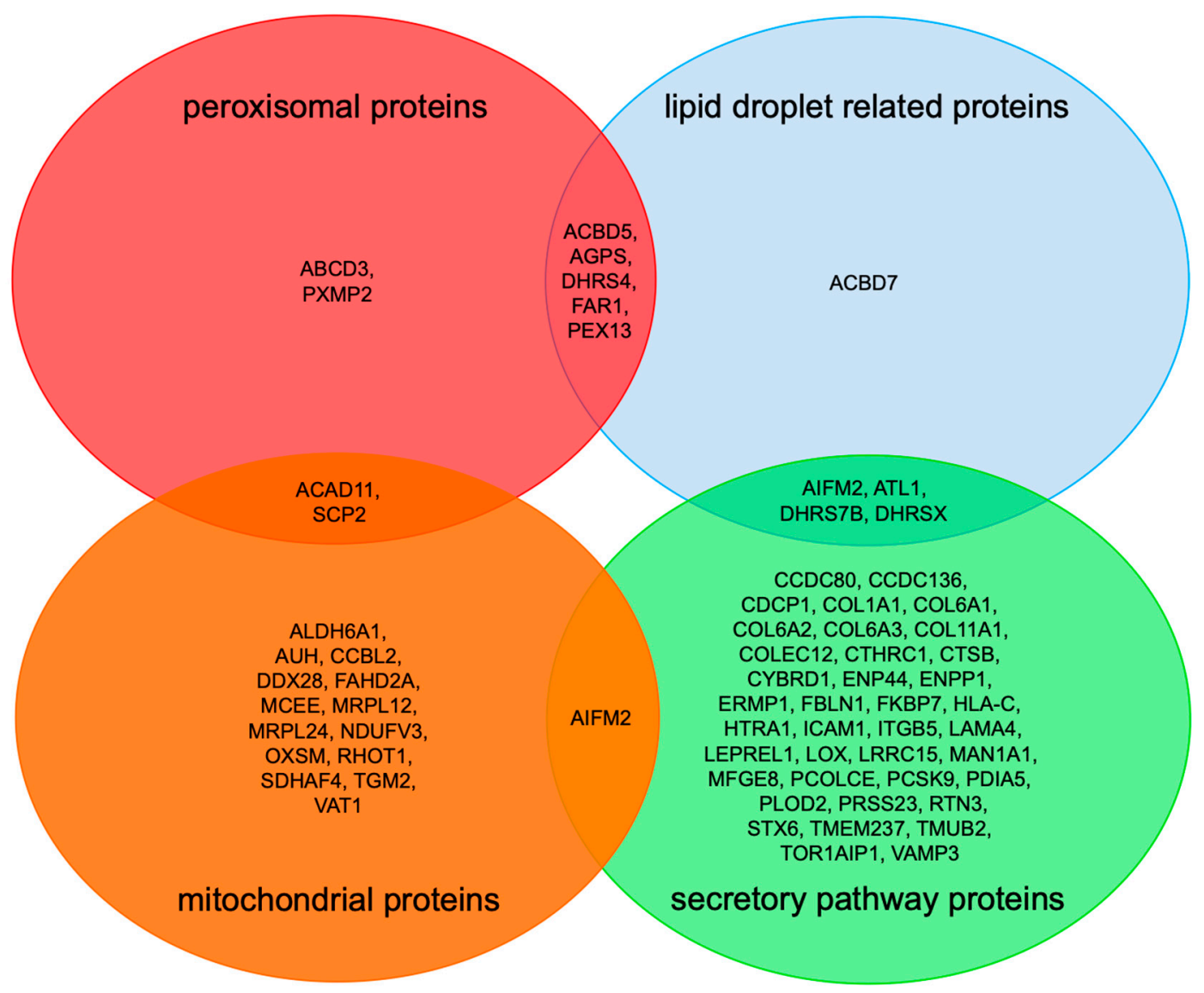

Figure 4. Venn diagram for negatively affected proteins in PEX3-deficient Zellweger patient fibroblasts. We note that Tables 3 and S4 served as the basis for this compilation.

In addition, the identified precursors included 27 proteins with cleavable SP, including five collagens and one collagen-like protein, four collagen-modifying proteins LE-REL1, three ER lumenal proteins, and the four plasma membrane proteins with a connection to the extracellular matrix or neighboring cells, i.e., CDCP1, ICAM1, ITGB5, LRRC15. Thus, between 14 and 17 of the total of 43 secretory pathway precursor proteins are collagens or related to collagens, which is a significant enrichment of $33-40 \%$. This raises the question of how PEX3 could be involved in the targeting of these precursors, which are expected to involve a cotranslational targeting pathway to the Sec61 complex. We hypothesize that, in these particular cases, PEX3 may act in concert with mRNA targeting pathways, which would be consistent with the observation that RRBP1-mediated targeting pathways were found to be involved in the biogenesis of these proteins [30,33]. However, their degradation in the absence of PEX3 may have an alternative explanation. We speculate that the combination of farnesylated PEX19 and ER-membrane-resident PEX3 targets the membrane-shaping and hairpin(s)-containing membrane proteins (such as Atlastins, Reticulons and Spastin) to the PEX3-rich ER subdomain, and that this enrichment of hairpin proteins creates an environment which attracts collagens as well as some of their modifying enzymes and future interaction partners [6,58-61]. As is consistent with this scenario, the key player of the formation of large cargo secretory vesicles at ER exit sites, the membrane protein TANGO1, has two transmembrane domains, one of which is supposed to form a hairpin in the inner leaflet of the ER membrane [59,60]. Either way, a common ER subdomain may be conducive to the budding of both peroxisomal precursor vesicles and large cargo secretory vesicles, as well as the formation of LDs. Indeed, very recent evidence suggests that membrane bridges between ER exit sites and LDs allow the protein partitioning of hairpin proteins from the ER to LDs (doi: https: / doi.org/10.1101/2021.09. 
14.460330; accessed on 25 November 2021). In addition, this observation raises the question of whether defects in collagen biogenesis contribute to the devastating effects of PEX3 deficiency in Zellweger patients, which clearly warrants further work.

Furthermore, negatively affected proteins in PEX3-depleted or -deficient human cells need to be discussed with respect to LD biogenesis from a functional point of view (Figure 3, Table 3). DHRS- and ACBD-family proteins, which were negatively affected in PEX3-deficient fibroblasts (Table 3) and the dehydrogenase/reductase SDR family members 4, $X$ and 7B (DHRS4, DHRSX, DHRS7B) play important roles in retinol biosynthesis, and may also localize to LDs [62]. The latter was suggested for DHRSX, and was actually shown for the family members DHRS3 and DHRS7B [62] (doi: https:/ /doi.org/10.110 $1 / 2021.09 .14 .460330)$. On the other hand, acyl-CoA-binding domain-containing proteins 5 and 7 (peroxisomal ACBD5, cytosolic ACBD7) are involved in organelle contacts and, therefore, may be important for lipid metabolism and/or organelle budding from the ER. These aspects, too, warrant further studies.

Taken together, our study revealed a putative client spectrum for PEX3-mediated protein targeting to the ER, including several unexpected protein classes, such as secreted collagens. Importantly, several PEX3 client candidates are involved in lipid metabolic pathways or membrane-shaping mechanisms, which affect the ER-derived organelle biogenesis of peroxisomes and/or LDs. As observed for other ER targeting pathways, PEX3 also likely shares some of its putative clients with other ER targeting components, including the Sec61 complex.

\section{Materials and Methods}

\subsection{Cell Growth and Analysis}

HeLa Kyoto cells [36] were cultivated at $37^{\circ} \mathrm{C}$ in a humidified environment with 5\% $\mathrm{CO}_{2}$, in DMEM with 10\% fetal bovine serum (FBS; Sigma-Aldrich, Taufkirchen, Germany). The cell growth and viability were monitored using the Countess ${ }^{\circledR}$ Automated Cell Counter (Invitrogen, Thermo Fisher Scientific, Darmstadt, Germany), following the manufacturer's instructions.

For gene silencing, $4 \times 10^{5}$ HeLa cells were seeded per 6-cm culture plate, followed by incubation under normal culture conditions. Next, the cells were transfected with either PEX3-targeting Silencer Select pre-designed siRNA (Life Technologies, Darmstadt, Germany, IDs s16154 and s16156) or with a scrambled siRNA control (Life Technologies ID 4390843) at a final concentration of $3.3 \mathrm{nM}$ using Lipofectamine 2000 (Life Technologies), following the manufacturer's instructions. After $48 \mathrm{~h}$, the cells were transfected a second time and grown for an additional $48 \mathrm{~h}$. Thus, silencing was performed for a total of 96 $\mathrm{h}$ using two different siRNAs. We note that the cell viability was not affected by PEX3 depletion for 96h, i.e., the viability values were virtually identical for the two PEX3targeting siRNAs (95.0\% for RNA\#1 and $96.0 \%$ for RNA\#2, $n=3$ ) versus the scrambled siRNA control $(95.7 \%)$.

The silencing efficiencies were evaluated by Western blot analysis using PEX3-specific antibodies [63] (1:1000 dilution), which were kindly donated by Gabriele Dodt (University of Tübingen, Tübingen, Germany) and anti-tubulin antibodies (T6199, Sigma-Aldrich; 1:10,000 dilution). Donkey-derived, Cy3- and Alexa488-conjugated secondary antibodies (715-165-151, 711-545-152, Jackson Immunoresearch, Cambridgeshire, UK) were detected using the Typhoon-Trio imaging system combined with Image Quant TL software 7.0 (GE Healthcare, Freiburg, Germany).

Immortalized PEX3-deficient fibroblasts and control fibroblasts were obtained from Gabriele Dodt (University of Tübingen, Tübingen, Germany), and were previously characterized $[41,64]$. They were cultivated at $37{ }^{\circ} \mathrm{C}$ in a humidified environment with $5 \% \mathrm{CO}_{2}$, in DMEM/GlutaMAX with 10\% fetal bovine serum (FBS; Sigma-Aldrich) for $72 \mathrm{~h}$. 


\subsection{Label-Free Quantitative Proteomic Analysis}

After growth for $96 \mathrm{~h}, 1 \times 10^{6}$ cells (corresponding to roughly $0.2 \mathrm{mg}$ protein) were harvested, washed twice in PBS, and lysed in a buffer containing $6 \mathrm{M} \mathrm{GnHCl}, 20 \mathrm{mM}$ tris(2carboxyethyl)phosphine (TCEP; Pierce ${ }^{\mathrm{TM}}$, Thermo Fisher Scientific, Darmstadt, Germany), and $40 \mathrm{mM}$ 2-chloroacetamide (CAA; Sigma-Aldrich) in $100 \mathrm{mM}$ Tris, at pH 8.0 [33,46-48]. The lysate was heated to $95^{\circ} \mathrm{C}$ for $2 \mathrm{~min}$, and then sonicated in a Bioruptor sonicator (Diagenode, Seraing, Belgium) at the maximum power setting for 10 cycles of $30 \mathrm{~s}$ each. For a $10 \%$ aliquot of the sample, the entire process of heating and sonication was repeated once, and then the sample was diluted 10-fold with digestion buffer ( $25 \mathrm{mM}$ Tris, $\mathrm{pH} 8,10 \%$ acetonitrile). The protein extracts were digested for $4 \mathrm{~h}$ with Lysyl endoproteinase Lys-C (Wako Bioproducts, Fujifilm, Neuss, Germany, enzyme to protein ratio: 1:50), followed by the addition of trypsin (Promega, Heidelberg, Germany) for overnight digestion (at an enzyme to protein ratio of 1:100). The next day, a booster digestion was performed for $4 \mathrm{~h}$ using an additional dose of trypsin (enzyme to protein ratio: 1:100). After the digestion, a $10 \%$ aliquot of peptides (corresponding to about $2 \mu \mathrm{g}$ of peptides) were purified via SDBRPS StageTips [65], eluted as one fraction, and loaded for MS analysis. Purified samples were loaded onto a 50-cm column (inner diameter: 75 microns; packed in-house with ReproSil-Pur C18-AQ 1.9-micron beads, Dr. Maisch HPLC GmbH, Ammerbuch, Germany) via the autosampler of the Thermo Easy-nLC 1000 (Thermo Fisher Scientific) at $60{ }^{\circ} \mathrm{C}$. Using the nanoelectrospray interface, the eluting peptides were directly sprayed onto the benchtop Orbitrap mass spectrometer Q Exactive HF (Thermo Fisher Scientific) [66]. The peptides were loaded in buffer A $(0.1 \%(v / v)$ formic acid) at $250 \mathrm{~nL} / \mathrm{min}$, and the percentage of buffer B was ramped to $30 \%$ over $180 \mathrm{~min}$, followed by a ramp to $60 \%$ over $20 \mathrm{~min}$, then $95 \%$ over the next $10 \mathrm{~min}$, and maintained at $95 \%$ for another $5 \mathrm{~min}[33,47]$. The mass spectrometer was operated in a data-dependent mode, with survey scans from 300 to $1700 \mathrm{~m} / \mathrm{z}$ (resolution of $60,000 \mathrm{at} \mathrm{m} / \mathrm{z}=200$ ). $U p$ to 15 of the top precursors were selected and fragmented using higher energy collisional dissociation (HCD) with a normalized collision energy value of 28 [33,47]. The MS2 spectra were recorded at a resolution of $17,500($ at $\mathrm{m} / \mathrm{z}=200)$. The AGC targets for the MS and MS2 scans were set to 3E6 and 1E5, respectively, within a maximum injection time of 100 and $25 \mathrm{~ms}$ for the MS and MS2 scans, respectively. Dynamic exclusion was enabled in order to minimize the repeated sequencing of the same precursor ions, and was set to $30 \mathrm{~s}[33,47]$.

\subsection{Data Analysis}

The raw data were processed using the MaxQuant computational platform [67]. The peak list was searched against Human Uniprot databases, and the proteins were quantified across the samples using the label-free quantification algorithm in MaxQuant as the labelfree quantification (LFQ) intensities [68]. We note that LFQ intensities do not reflect true copy numbers because they depend not only on the amounts of the peptides but also on their ionization efficiencies; thus, they only served to compare the abundances of the same protein in different samples [66-71]. Each MS experiment provided proteomewide abundance data as LFQ intensities for three sample groups-one control (the nontargeting siRNA treated) and two stimuli (down-regulation by two different targeting siRNAs directed against the same gene)—with each having three data points. The missing data points were generated by imputation, whereby we distinguished two cases [46]. In order to identify which proteins were affected by PEX3 knock-down in siRNA-treated cells relative to the non-targeting (control) siRNA-treated sample, we log2-transformed the ratio between siRNA and the control siRNA samples, and performed two separate unpaired $t$-tests for each siRNA against the control siRNA sample [46]. The $p$ values obtained by the unpaired $t$-tests were corrected for multiple testing using a permutationbased false discovery rate (FDR) test. The proteins with an FDR-adjusted $p$ value of below $5 \%$ were considered to be significantly affected by the knockdown of the targeted protein. The results from the two unpaired $t$-tests were then intersected for further analysis, meaning that the abundance of all of the reported candidates was statistically significantly 
affected in both siRNA silencing experiments. For completely missing proteins lacking any valid data points, the imputed data points were randomly generated in the bottom tail of the whole proteomics distribution, following the strategy in the Perseus software (http://maxquant.net/perseus/; last accessed on 2 May 2021) [70]. For proteins with at least one valid MS data point, the missing data points were generated from the valid data points based on the local least squares (LLS) imputation method [71]. The validity of this approach was demonstrated [46]. Subsequent to the data imputation, gene-based quantile normalization was applied to homogenize the abundance distributions of each protein with respect to the statistical properties. All of the statistical analyses were performed using the R package of SAM (https:/ / statweb.stanford.edu/ tibs/SAM/; last accessed on 2 May 2021) [72]. The protein annotations of the signal peptides, transmembrane regions, and N-glycosylation sites in humans and yeast were extracted from UniProtKB entries using custom scripts [46]. The enrichment of the functional Gene Ontology annotations (cellular components and biological processes) among the secondarily affected proteins was computed using the GOrilla package [73].

\subsection{Validation of Putative PEX3 Substrates by Quantitative Western Blotting}

Hits from the protemics analysis were validated by quantitative Western blot analyses of Triton-X100 cell lysates (1\% Triton X-100, $50 \mathrm{mM}$ Hepes pH 7.5, $150 \mathrm{mM} \mathrm{NaCl}, 10 \%$ glycerol, $1 \mathrm{mM}$ EDTA, $1 \mathrm{mM}$ PMSF, Complete EDTA-free protease inhibitors (Roche)) using the following antibodies: anti-PEX3 (gift from G. Dodt; 1:1000 dilution), anti-ACBD5 (HPA012145 Merck, Taufkirchen, Germany; 1:1000 dilution), anti-RTN3 (12055-2-AP Proteintech, Manchester, UK; 1:1000 dilution), anti-PDIA5 (15545-1 Proteintech; 1:1000 dilution), anti-Far1 (ATA-HPA017322 Biozol, Eching, Germany; 1:1250 dilution), and antitubulin (T6199, Sigma-Aldrich; 1:10,000 dilution), which served as a loading control for normalization. The secondary antibodies were purchased from Licor Biosciences, Bad Homburg, Germany (926-68020, 926-68021, 926-32211, 926-32210, all in 1:20,000 dilution). The signals were detected using the Odyssey Clx system from Licor Biosciences, and were quantified by densitometry using the Image Studio software (Licor Biosciences). The relative protein abundance was calculated as the ratio of the signal of interest to the corresponding tubulin signal in the same lane, and was normalized against one control sample. The visualization of the quantification data was performed using Graphpad Prism software.

\section{Conclusions}

Recent studies characterized the PEX19/PEX3 pathway, which is best known for its role in the biogenesis of peroxisomal membrane proteins both at the peroxisomal and the ER membrane, as being involved in the biogenesis of hairpin membrane proteins of the ER as well as LDs. Therefore, the question arose as to whether this pathway may play a more general role in ER protein targeting, i.e., whether it may represent a fourth pathway for the ER targeting of precursor polypeptides next to SRP, SND, and TRC/GET. We have started to address this question by a novel approach which involves the label-free quantitative mass spectrometry of the total proteome of depleted or deficient cells, along with differential protein abundance analysis. Thus, we addressed the client spectrum of the PEX19/PEX3dependent pathway in both PEX3 targeting siRNA-treated HeLa cells and PEX3-deficient Zellweger patient fibroblasts. The negatively affected proteins included six peroxisomal membrane proteins and two hairpin proteins of the ER, thus confirming the two previously identified classes of putative PEX19/PEX3 clients for ER targeting in human cells, as well as the validity of the experimental approach. In addition, 14 membrane proteins (including four tail-anchored proteins) and 27 proteins with SP (including 14 collagens and collagenrelated proteins) belonging to the secretory pathway were also negatively affected by PEX3 deficiency. The latter findings are consistent with the idea that PEX3 represents a fourth pathway for the targeting of precursor polypeptides to the Sec61 complex. Furthermore, it may suggest a hitherto unknown spatial—or at least physical—relationship between the 
ER subdomains that are involved in ER shaping and the budding of peroxisomal precursor vesicles, large cargo vesicles, and lipid droplets. In addition, these results may suggest compromised collagen biogenesis as a hitherto unknown contributor to organ failures in the respective Zellweger patients. All of these suggestions will have to be addressed in future research.

Supplementary Materials: The Supplementary Materials are available online at https:/ /www.mdpi. com/article/10.3390/ijms222313028/s1.

Author Contributions: R.Z. and B.S. planned and supervised the sample generation for the MS analysis and validation experiments by M.L., D.N. performed the MS data analysis under supervision by V.H., F.F. and R.Z. designed the study. R.Z. and B.S. wrote the manuscript together with F.F., S.L. and V.H. All of the authors discussed the results. All authors have read and agreed to the published version of the manuscript.

Funding: F.F., V.H., S.L., B.S. and R.Z. were supported by the Deutsche Forschungsgemeinschaft (DFG, German Research Foundation), with grants FO716/4-1 to F.F., HE3875/15-1 to V.H., ZI234/131 to R.Z., IRTG1830 and SFB894 to S.L. and R.Z, and SFB1027 to B.S. Furthermore, the authors acknowledge support from the the Deutsche Forschungsgemeinschaft (DFG, German Research Foundation) and Saarland University within the funding programme Open Access Publishing.

Data Availability Statement: The novel MS proteomics data were deposited to the ProteomeXchange Consortium via the PRIDE partner repository, with the dataset identifier PXD012005 (http:/ /www. proteomexchange.org, accessed on 18 October 2021). In addition, all of the data are available from the authors.

Acknowledgments: The authors thank Nagarjuna Nagaraj (Max-Planck Institute of Biochemistry, Biochemistry core facility, Martinsried, Germany) for the MS analyses, Silke Guthörl (Saarland University, Homburg, Germany) for the technical assistance, and Gabriele Dodt (University of Tübingen, Tübingen, Germany) for providing anti-PEX3 antibodies, as well as the immortalized PEX3-deficient cells and control fibroblasts.

Conflicts of Interest: The authors declare no conflict of interest.

$\begin{array}{ll}\text { Abbreviations } \\ \text { ATL } & \text { Atlastin } \\ \text { CDG } & \text { Congenital disorder of glycosylation } \\ \text { EMC } & \text { ER membrane complex } \\ \text { ER } & \text { Endoplasmic reticulum } \\ \text { GET } & \text { Guided entry of tail-anchored proteins } \\ \text { GO } & \text { Gene ontology } \\ \text { GPI } & \text { Glycosylphosphatidylinositol } \\ \text { LD } & \text { Lipid droplet } \\ \text { PEX } & \text { Peroxin } \\ \text { RAMP } & \text { Ribosome-associated membrane protein } \\ \text { RNC } & \text { Ribosome-nascent chain complex } \\ \text { RTN } & \text { Reticulon } \\ \text { SEC } & \text { (Protein involved in) secretion } \\ \text { SND } & \text { SRP-independent } \\ \text { SP } & \text { Signal peptide } \\ \text { SR } & \text { SRP receptor } \\ \text { SRP } & \text { Signal recognition particle } \\ \text { SSR } & \text { Signal sequence receptor } \\ \text { TMEM } & \text { Transmembrane (protein) } \\ \text { TMH } & \text { Transmembrane helix } \\ \text { TRAM } & \text { translocating chain-associating membrane (protein) } \\ \text { TRAP } & \text { Translocon-associated protein } \\ \text { TRC } & \text { Transmembrane recognition complex } \\ \text { Z } & \text { Zellweger (patient fibroblasts) } \\ & \\ & \end{array}$




\section{References}

1. Dudek, J.; Pfeffer, S.; Lee, P.-H.; Jung, M.; Cavalié, A.; Helms, V.; Förster, F.; Zimmermann, R. Protein transport into the human endoplasmic reticulum. J. Mol. Biol. 2015, 427, 1159-1175. [CrossRef]

2. Aviram, N.; Schuldiner, M. Targeting and translocation of proteins to the endoplasmic reticulum at a glance. J. Cell Sci. 2017, 130, 4079-4085. [CrossRef] [PubMed]

3. Gemmer, M.; Förster, F. A clearer picture of the ER translocon complex. J. Cell Sci. 2020, 133, jcs231340. [CrossRef] [PubMed]

4. O'Keefe, S.; Pool, M.R.; High, S. Membrane protein biogenesis at the ER: The highways and byways. FEBS J. 2021. [CrossRef]

5. Budnik, A.; Stephens, D.J. ER exit sites-Localization and control of COPII vesicle formation. FEBS Lett. 2009, 583, 3796-3803. [CrossRef] [PubMed]

6. $\quad$ Stephens, D.J. Collagen secretion explained. Nature 2012, 482, 474-475. [CrossRef]

7. Schrul, B.; Schliebs, W. Intracellular communication between lipid droplets and peroxisomes: The Janus face of PEX19. Biol. Chem. 2018, 399, 741-749. [CrossRef]

8. Jansen, R.L.M.; van der Klei, I.J. The peroxisome biogenesis factors Pex3 and Pex19: Multitasking proteins with disputed functions. FEBS Lett. 2019, 593, 457-474. [CrossRef]

9. Dhimann, R.; Caesar, S.; Thiam, A.R.; Schrul, B. Mechanisms of protein targeting to lipid droplets: A unified cell biological and biophysical perspective. Sem. Cell Dev. Biol. 2020, 108, 4-13. [CrossRef]

10. Goodman, J.M. Building the lipid droplet assembly complex. J. Cell Biol. 2020, 219, e202006025. [CrossRef] [PubMed]

11. Hansen, K.G.; Aviram, N.; Laborenz, J.; Bibi, C.; Meyer, M.; Spang, A.; Schuldiner, M.; Herrmann, J.M. An ER surface retrieval pathway safeguaerds the import of mitochondrial membrane proteins in yeast. Science 2018, 361, 1118-1122. [CrossRef]

12. Hegde, R.S.; Bernstein, H. The surprising complexity of signal peptides. Trends Biochem. Sci. 2006, 31, 563-571. [CrossRef]

13. Goder, V.; Spiess, M. Molecular mechanism of signal sequence orientation in the endoplasmic reticulum. EMBO J. 2003, 22, 3645-3653. [CrossRef] [PubMed]

14. Goder, V.; Junne, T.; Spiess, M. Sec61p contributes to signal sequence orientation according to the positive-inside rule. Mol. Biol. Cell 2004, 15, 1470-1478. [CrossRef]

15. Borgese, N.; Fasana, E. Targeting pathways of C-tail-anchored proteins. Biochim. Biophys. Acta 2011, 1808, 937-946. [CrossRef]

16. Yamamoto, Y.; Sakisaka, T. Molecular machinery for insertion of tail-anchored membrane proteins into the endoplasmic reticulum membrane in mammalian cells. Mol. Cell 2012, 48, 387-397. [CrossRef] [PubMed]

17. Borgese, N.; Coy-Vergara, J.; Colombo, S.F.; Schwappach, B. The ways of tails: The GET pathway and more. Proteins 2019, 38, 289-305. [CrossRef]

18. Abell, B.M.; High, S.; Moloney, M.M. Membrane protein topology of oleosin is constrained by its long hydrophobic domain. J. Biol. Chem. 2002, 277, 8602-8610. [CrossRef]

19. Leznicki, P.; Schneider, H.O.; Harvey, J.V.; Shi, W.Q.; High, S. Co-translational biogenesis of lipid droplet integral membrane proteins. J. Cell Sci. 2021, 132, jcs.259220. [CrossRef]

20. Gamerdinger, M.; Hanebuth, M.A.; Frickey, T.; Deuerling, E. The principle of antagonism ensures protein targeting specificity at the endoplasmic reticulum. Science 2015, 348, 201-207. [CrossRef]

21. Hsieh, H.-H.; Lee, J.H.; Chandrasekar, S.; Shan, S.-o. A ribosome-associated chaperone enables sustrate triage in a cotranslational protein targeting complex. Nat. Commun. 2020, 11, 5840. [CrossRef]

22. Aviram, N.; Ast, T.; Costa, E.A.; Arakel, E.; Chuartzman, S.G.; Jan, C.H.; Haßdenteufel, S.; Dudek, J.; Jung, M.; Schorr, S.; et al. The SND proteins constitute an alternative targeting route to the endoplasmic reticulum. Nature 2016, 540, 134-138. [CrossRef]

23. Casson, J.; McKenna, M.; Haßdenteufel, S.; Aviram, N.; Zimmermann, R.; High, S. Multiple pathways facilitate the biogenesis of mammalian tail-anchored proteins. J. Cell Sci. 2017, 130, 3851-3861. [CrossRef]

24. Haßdenteufel, S.; Sicking, M.; Schorr, S.; Aviram, N.; Fecher-Trost, C.; Schuldiner, M.; Jung, M.; Zimmermann, R.; Lang, S. hSnd2 protein represents an alternative targeting factor to the endoplasmic reticulum in human cells. FEBS Lett. 2017, 591, 3211-3224. [CrossRef]

25. Haßdenteufel, S.; Johnson, N.; Paton, A.W.; Paton, J.C.; High, S.; Zimmermann, R. Chaperone-mediated Sec61 channel gating during ER import of small precursor proteins overcomes Sec61 inhibitor-reinforced energy barrier. Cell Rep. 2018, 23, 1373-1386. [CrossRef]

26. Haßdenteufel, S.; Nguyen, D.; Helms, V.; Lang, S.; Zimmermann, R. Components and mechanisms for ER import of small human presecretory proteins. FEBS Lett. 2019, 593, 2506-2524. [CrossRef]

27. Cui, X.A.; Zhang, H.; Palazzo, A.F. p180 promotes the ribosome-independent localization of a subset of mRNA to the endoplasmic reticulum. PLoS Biol. 2012, 10, e1001336. [CrossRef]

28. Cui, X.A.; Zhang, Y.; Hong, S.J.; Palazzo, A.F. Identification of a region within the placental alkaline phosphatase mRNA that mediates p180-dependent targeting to the endoplasmic reticulum. J. Biol. Chem. 2013, 288, 29633-29641. [CrossRef] [PubMed]

29. Calvin, H.J.; Williams, C.C.; Weissman, J.S. Principles of ER coranslational translocation revealed by proximity-specific ribosome profiling. Science 2014, 346, 1257521. [CrossRef]

30. Ueno, T.; Tanaka, K.; Kaneko, K.; Taga, Y.; Sata, T.; Irie, S.; Shunji Hattori, S.; Ogawa-Goto, K. Enhancement of procollagen biosynthesis by 180 through augmented ribosome association on the endoplasmic reticulum in response to stimulated secretion. J. Biol. Chem. 2010, 285, 29942-29950. [CrossRef] [PubMed] 
31. Hsu, J.C.-C.; Reid, D.W.; Hoffman, A.M.; Sarkar, D.; Nicchitta, C.V. Oncoprotein AEG-1 is an endoplasmic reticulum RNA-binding protein whose interactome is enriched in organelle resident protein-encoding mRNAs. RNA 2018, 24, 688-703. [CrossRef]

32. Hannigan, M.M.; Hoffman, A.M.; Thompson, J.W.; Zheng, T.; Nicchitta, C.V. Quantitative proteomics links the LRRC59 interactome to mRNA translation on the ER membrane. Mol. Cell. Proteom. 2020, 19, 1826-1849. [CrossRef]

33. Bhadra, P.; Schorr, S.; Lerner, M.; Nguyen, D.; Dudek, J.; Förster, F.; Helms, V.; Lang, S.; Zimmermann, R. Quantitative proteomics and differential protein abundance analysis after depletion of putative mRNA receptors in the ER membrane of human cells identifies novel aspects of mRNA targeting to the ER. Molecules 2021, 26, 3591. [CrossRef] [PubMed]

34. Sicking, M.; Lang, S.; Bochen, F.; Drenth, J.P.H.; Zacharia, M.; Zimmermann, R.; Roos, A.; Linxweiler, M. Complexity and specificity of sec61-channelopathies: Human diseases affecting gating of the Sec61 complex. Cells 2021, 10, 1036. [CrossRef]

35. Yamamoto, Y.; Sakisaka, T. The peroxisome biogenesis factors posttranslationally target reticulon homology-domain containing proteins to the endoplasmic reticulum membrane. Sci. Rep. 2018, 8, 2322. [CrossRef] [PubMed]

36. Schrul, B.; Kopito, R.R. Peroxin-dependent targeting of a lipid-droplet-destined membrane protein to ER subdomains. Nat. Cell Biol. 2016, 18, 740-751. [CrossRef] [PubMed]

37. Dahan, N.; Francisco, T.; Falter, C.; Rodrigues, T.; Kalel, V.; Kunze, M.; Hansen, T.; Schliebs, W.; Erdmann, R. Current advances in the function and biogenesis of peroxisomes and their roles I health and disease. Hist. Cell Biol. 2021, 155, 513-524. [CrossRef]

38. Erdmann, R.; Veenhuis, M.; Mertens, D.; Kunau, W.-H. Isolation of peroxisome-deficient mutants of Saccharomyces cerevisiae. Proc. Natl. Acad. Sci. USA 1989, 86, 5419-5423. [CrossRef]

39. Götte, K.; Girzalsky, W.; Linkert, M.; Baumgart, E.; Kammerer, S.; Hunau, W.-H.; Erdmann, R. Pex19p, a farnesylated protein essential for peroxisome biogenesis. Mol. Cell. Biol. 1998, 18, 616-628. [CrossRef] [PubMed]

40. Hettema, E.H.; Girzalsky, W.; van den Berg, M.; Erdmann, R.; Distel, B. Saccharomyces cerevisiae Pex3p and Pex19p are required for proper localization and stability of peroxisomal membrane proteins. EMBO J. 2000, 19, 223-233. [CrossRef] [PubMed]

41. Schmidt, F.; Dietrich, D.; Eylenstein, R.; Groemping, Y.; Stehle, T.; Dodt, G. The role of conserved PEX3 regions in PEX19-binding and peroxisome biogenesis. Traffic 2012, 13, 1244-1260. [CrossRef]

42. Muntau, A.C.; Maerhofer, P.U.; Paton, B.C.; Kammerer, S.; Roscher, A.A. Defective peroxisome membrane synthesis due to mutations in human PEX3 causes Zellweger syndrome, complementation group G. Am. J. Hum. Genet. 2000, 67, 967-975. [CrossRef]

43. Shimozawa, N.; Suzuki, Y.; Zhang, Z.; Imamura, A.; Ghaedi, K.; Fujiki, Y.; Kondo, N. Identification of PEX3 as the gene mutated in a Zellweger syndrome patient lacking peroxisomal remnant structures. Hum. Mol. Genet. 2000, 9, 1995-1999. [CrossRef] [PubMed]

44. Ghaedi, K.; Honsho, M.; Shimozawa, N.; Suzuki, Y.; Kondo, N.; Fujiki, Y. PEX3 is the causal gene responsible for peroxisome membrane assembly-defective Zellweger syndrome of complementation group G. Am. J. Hum. Genet. 2000, 67, 976-981. [CrossRef] [PubMed]

45. Hein, M.Y.; Hubner, N.C.; Poser, I.; Cox, J.; Nagaraj, N.; Toyoda, Y.; Gak, I.A.; Weisswange, I.; Mansfeld, J.; Buchholz, F.; et al. A human interactome in three quantitative dimensions organized by stoichiometries and abundances. Cell 2015, 163, 712-723. [CrossRef] [PubMed]

46. Nguyen, D.; Stutz, R.; Schorr, S.; Lang, S.; Pfeffer, S.; Freeze, H.F.; Förster, F.; Helms, V.; Dudek, J.; Zimmermann, R. Proteomics reveals signal peptide features determining the client specificity in human TRAP-dependent ER protein import. Nat. Commun. 2018, 9, 37639. [CrossRef]

47. Schorr, S.; Nguyen, D.; Haßdenteufel, S.; Nagaraj, N.; Cavalié, A.; Greiner, M.; Weissgerber, P.; Loi, M.; Paton, A.W.; Paton, J.C.; et al. Proteomics identifies signal peptide features determining the substrate specificity in human Sec62/Sec63-dependent ER protein import. FEBS J. 2020, 287, 4612-4640. [CrossRef]

48. Klein, M.-C.; Lerner, M.; Nguyen, D.; Pfeffer, S.; Dudek, J.; Förster, F.; Helms, V.; Lang, S.; Zimmermann, R. TRAM1 protein may support ER protein import by modulating the phospholipid bilayer near the lateral gate of the Sec61 channel. Channels 2020, 14, 28-44. [CrossRef] [PubMed]

49. Vizcaíno, J.A.; Csordas, A.; del-Toro, N.; Dianes, J.A.; Griss, J.; Lavidas, I.; Mayer, G.; Perez-Riverol, Y.; Reisinger, F.; Ternent, T.; et al. 2016 update of the PRIDE database and related tools. Nucleic Acids Res. 2016, 44, D447-D456. [CrossRef]

50. Cichocki, B.A.; Krumpe, K.; Vitali, D.G.; Rapaport, D. Pex19 is involved in importing dually targeted tail-anchored proteins to both mitochondria and peroxisomes. Traffic 2018, 19, 770-785. [CrossRef]

51. Exner, T.; Romero-Brey, I.; Yifrach, E.; Rivera-Monroy, J.; Schrul, B.; Zouboulis, C.C.; Stremmel, W.; Honsho, M.; Bartenschlager, R.; Zalckvar, E.; et al. An alternative membrane topology permits lipid droplet localization of peroxisomal fatty acyl-CoA reductase 1. J. Cell Sci. 2021, 132, jcs223016. [CrossRef]

52. Agarwal, A.K.; Sukumaran, S.; Cortés, V.A.; Tunison, K.; Mizrachi, D.; Sankella, S.; Gerard, R.D.; Horton, J.D.; Garg, A. Human 1-acylglycerol-3-phosphate O-acyltransferase isoforms 1 and 2: Biochemical characterization and inability to rescue hepatic steatosis in Agpat2(-/-) gene lipodystrophic mice. J. Biol. Chem. 2011, 286, 37676-37691. [CrossRef]

53. He, W.; Shi, Q.; Hu, X.; Yan, R. The membrane topology of RTN3 and its effect on binding of RTN3 to BACE1. J. Biol. Chem. 2007, 282, 29144-29151. [CrossRef]

54. Mayerhofer, P.U.; Bano-Polo, M.; Mingarro, I.; Johnson, A.E. Human peroxin PEX3 is co-translationally integrated into the ER and exits the ER in budding vesicles. Traffic 2016, 17, 117-130. [CrossRef] [PubMed] 
55. Brar, G.A.; Weissman, J.S. Ribosome profiling reveals the what, when, where, and how of protein synthesis. Nat. Rev. Mol. Cell Biol. 2015, 16, 651-664. [CrossRef]

56. Pfeiffer, N.V.; Dirndorfer, D.; Lang, S.; Resenberger, U.K.; Restelli, L.M.; Hemion, C.; Miesbauer, M.; Frank, S.; Neutzner, A.; Zimmermann, R.; et al. Structural features within the nascent chain regulate alternative targeting of secretory proteins to mitochondria. EMBO J. 2013, 32, 1036-1051. [CrossRef] [PubMed]

57. Nuebel, E.; Morgan, J.T.; Fogarty, S.; Winter, J.M.; Lettlova, S.; Berg, J.A.; Chen, Y.-C.; Kidwell, C.U.; Maschek, J.A.; Clowers, K.J.; et al. The biochemical basis of mitochondrial dysfunction in Zellweger spectrum disorder. EMBO Rep. 2021, 22 , e51991. [CrossRef] [PubMed]

58. Chen, C.; Li, J.; Qin, X.; Wang, W. Peroxisomal membrane contact sites in mammalian cells. Front. Cell Dev. Biol. 2020, 8, 512. [CrossRef]

59. Saito, K.M.; Chen, F.; Bard, S.; Chen, H.; Zhou, D.; Woodley, R.; Polischuk, R.; Schekman, R.; Malhotra, V. TANGO1 facilitates cargo loading at endoplasmic reticulum exit sites. Cell 2009, 136, 891-902. [CrossRef] [PubMed]

60. Raote, I.; Ortega-Bellido, M.; Santos, A.J.M.; Foresti, O.; Zhang, C.; Garcia-Parajo, M.F.; Campelo, F.; Malhotra, V. TANGO1 builds a machine for collagen export by recruiting and spatially organizing COPII, thethers and membranes. eLife 2018, 7, e32723. [CrossRef]

61. Raote, I.; Ernst, A.M.; Campelo, F.; Rothman, J.; Pincet, F.; Malhotra, V. TANGO1 membrane helices create a lipid diffusion barrier at curved membranes. eLife 2020, 9, e57822. [CrossRef]

62. Pataki, C.I.; Rodrigues, J.; Zhang, L.; Qian, J.; Efron, B.; Hastie, T.; Elias, J.E.; Levitt, M.; Kopito, R.R. Proteomic analysis of monolayer-integrated proteins of lipid droplets identifies amphipathic interfacial $\alpha$-helical membrane anchors. Proc. Natl. Acad. Sci. USA 2018, 115, E8172-E8180. [CrossRef]

63. Pinto, M.P.; Grou, C.P.; Fransen, M.; Fransen, M.; Sa-Miranda, C. The cytosolic domain of PEX3, a protein inolved in the biogenesis of peroxisomes, binds membrane lipids. Biochem. Biophys. Acta 2009, 1793, 1669-1675. [CrossRef] [PubMed]

64. Poulos, A.; Christodoulou, J.; Chow, C.W.; Goldblatt, J.; Paton, B.C.; Orii, T.; Suzuki, Y.; Shimozawa, N. Peroxisomal assembly defects: Clinical, pathologic, and biochemical findings in two patients in a newly identified complementation group. J. Pediatr. 1995, 127, 596-599. [CrossRef]

65. Rappsilber, J.; Mann, M.; Ishihama, Y. Protocol for micro-purification, enrichment, pre-fractionation and storage of peptides for proteomics using StageTips. Nat. Protoc. 2007, 2, 1896-1906. [CrossRef]

66. Nagaraj, N.; Kulak, N.A.; Cox, J.; Neuhauser, N.; Mayr, K.; Hoerning, O.; Vorm, O.; Mann, M. System-wide perturbation analysis with nearly complete coverage of the yeast proteome by single-shot ultra HPLC runs on a bench top Orbitrap. Mol. Cell. Proteom. 2012, 11, M111.013722. [CrossRef]

67. Cox, J.; Mann, M. MaxQuant enables high peptide identification rates, individualized p.p.b.-range mass accuracies and proteomewide protein quantification. Nat. Biotechnol. 2008, 26, 1367-1372. [CrossRef] [PubMed]

68. Cox, J.; Hein, M.Y.; Luber, C.A.; Paron, I.; Nagaraj, N.; Mann, M. Accurate proteome-wide label-free quantification by delayed normalization and maximal peptide ratio extraction, termed MaxLFQ. Mol. Cell. Proteom. 2014, 13, 2513-2526. [CrossRef]

69. Nagaraj, N.; Wisniewski, J.R.; Geiger, T.; Cox, J.; Kircher, M.; Kelso, J.; Pääbo, S.; Mann, M. Deep proteome and transcriptome mapping of a human cancer cell line. Mol. Sys. Biol. 2011, 7, 548. [CrossRef]

70. Tyanova, S.; Temu, T.; Sinitcyn, P.; Carlson, A.; Hein, M.Y.; Geiger, T.; Mann, M.; Coc, J. The Perseus computational platform for comprehensive analysis of (proteo)omics data. Nature Meth. 2016, 13, 731-740. [CrossRef] [PubMed]

71. Hyunsoo, K.; Golub, G.H.; Park, H. Missing value estimation for DNA microarray gene expression data: Local least squares imputation. Bioinformatics 2005, 21, 187-198. [CrossRef]

72. Tusher, V.G.; Tibshirani, R.; Chu, G. Significance analysis of microarrays applied to the ionizing radiation response. Proc. Natl. Acad. Sci. USA 2001, 98, 5116-5121. [CrossRef] [PubMed]

73. Eden, E.; Navon, R.; Steinfeld, I.; Lipson, D.; Yakhini, Z. Gorilla: A tool for discovery and visualization of enriched GO terms in ranked gene lists. BMC Bioinform. 2009, 10, 48. [CrossRef] [PubMed] 